\title{
Strategies to Prevent Ventilator-Associated Pneumonia in Acute Care Hospitals: 2014 Update
}

\section{Citation}

Klompas, Michael, Richard Branson, Eric C. Eichenwald, Linda R. Greene, Michael D. Howell, Grace Lee, Shelley S. Magill, et al. 2014. "Strategies to Prevent Ventilator-Associated Pneumonia in Acute Care Hospitals: 2014 Update." Infection Control \& Hospital Epidemiology 35 (S2): S13354. doi:10.1017/S0899823X00193894.

\section{Permanent link}

http://nrs.harvard.edu/urn-3:HUL.InstRepos:41542974

\section{Terms of Use}

This article was downloaded from Harvard University's DASH repository, and is made available under the terms and conditions applicable to Other Posted Material, as set forth at http:// nrs.harvard.edu/urn-3:HUL.InstRepos:dash.current.terms-of-use\#LAA

\section{Share Your Story}

The Harvard community has made this article openly available. Please share how this access benefits you. Submit a story.

Accessibility 


\title{
Strategies to Prevent Ventilator-Associated Pneumonia in Acute Care Hospitals: 2014 Update
}

\author{
Michael Klompas, MD, MPH; ${ }^{1,2}$ Richard Branson, MSc, RRT; ${ }^{3}$ Eric C. Eichenwald, MD; ${ }^{4}$ \\ Linda R. Greene, RN, MPS, CIC; ${ }^{5}$ Michael D. Howell, MD, MPH; ${ }^{6}$ Grace Lee, MD; \\ Shelley S. Magill, MD, PhD; ${ }^{8}$ Lisa L. Maragakis, MD, MPH; ${ }^{9}$ Gregory P. Priebe, MD; ${ }^{2,7,10}$ \\ Kathleen Speck, MPH; ${ }^{11}$ Deborah S. Yokoe, MD, MPH; ${ }^{2}$ Sean M. Berenholtz, MD, MHS ${ }^{11,12,13}$
}

\section{PURPOSE}

Previously published guidelines are available that provide comprehensive recommendations for detecting and preventing healthcare-associated infections (HAIs). The intent of this document is to highlight practical recommendations in a concise format to assist acute care hospitals in implementing and prioritizing strategies to prevent ventilator-associated pneumonia (VAP) and other ventilator-associated events (VAEs) and to improve outcomes for mechanically ventilated adults, children, and neonates. This document updates "Strategies to Prevent Ventilator-Associated Pneumonia in Acute Care Hospitals," published in 2008. ${ }^{1}$ This expert guidance document is sponsored by the Society for Healthcare Epidemiology of America (SHEA) and is the product of a collaborative effort led by SHEA, the Infectious Diseases Society of America (IDSA), the American Hospital Association (AHA), the Association for Professionals in Infection Control and Epidemiology (APIC), and The Joint Commission, with major contributions from representatives of a number of organizations and societies with content expertise. The list of endorsing and supporting organizations is presented in the introduction to the 2014 updates. $^{2}$

\section{SECTION 1: RATIONALE AND STATEMENT OF CONCERNS}

I. Patients on mechanical ventilation are at high risk for VAP and other complications

A. The true incidence of VAP is difficult to determine since surveillance definitions are subjective and nonspecific. Historically, $10 \%-20 \%$ of ventilated patients have developed VAP. More recent reports suggest much lower rates, but it is unclear to what extent these lower rates reflect better care versus stricter application of subjective surveillance criteria. ${ }^{3,4}$ Notwithstanding surveillance rates that hover near zero, clinical surveys suggest that $5 \%-15 \%$ of ventilated patients still develop nosocomial pneumonias. ${ }^{5-9}$

B. Patients on mechanical ventilation are at risk for a variety of serious complications in addition to pneumonia. These include acute respiratory distress syndrome, pneumothorax, pulmonary embolism, lobar atelectasis, and pulmonary edema. The Centers for Disease Control and Prevention (CDC) released new surveillance definitions for VAE designed to make surveillance more objective and to expand surveillance from VAP alone to include additional serious complications of mechanical ventilation (see section 2). VAE definitions include criteria for ventilator-associated conditions (VACs), infection-related ventilator-associated complications (IVACs), possible pneumonia, and probable pneumonia. Approximately $5 \%-10 \%$ of mechanically ventilated patients develop VAEs. ${ }^{10-16}$

II. VAP and other complications of mechanical ventilation are detrimental to patients and increase costs

A. The attributable mortality of VAP is estimated to be approximately $10 \%$ but varies considerably for different kinds of patients. ${ }^{17-20}$

Affiliations: 1. Department of Population Medicine, Harvard Medical School and Harvard Pilgrim Health Care Institute, Boston, Massachusetts; 2. Department of Medicine, Brigham and Women's Hospital, Boston, Massachusetts; 3. Department of Surgery, University of Cincinnati, Ohio; 4. Division of Neonatal-Perinatal Medicine, University of Texas Medical School at Houston, Houston, Texas; 5. Highland Hospital, University of Rochester Medical Center Affiliate, Rochester, New York; 6. Department of Medicine, University of Chicago, Chicago, Illinois; 7. Department of Medicine, Boston Children's Hospital, Boston, Massachusetts; 8. Division of Healthcare Quality Promotion, Centers for Disease Control and Prevention, Atlanta, Georgia; 9. Department of Medicine, Johns Hopkins University School of Medicine, Baltimore, Maryland; 10. Department of Anesthesiology, Perioperative and Pain Medicine, Boston Children's Hospital, Boston, Massachusetts; 11. Department of Anesthesiology and Critical Care Medicine, Johns Hopkins University School of Medicine, Baltimore, Maryland; 12. Department of Surgery, Johns Hopkins University School of Medicine, Baltimore, Maryland; 13. Department of Health Policy and Management, Bloomberg School of Public Health, Johns Hopkins University, Baltimore, Maryland.

Received April 14, 2014; accepted April 16, 2014; electronically published July 16, 2014. Infect Control Hosp Epidemiol 2014;35(8):915-936

(C) 2014 by The Society for Healthcare Epidemiology of America. All rights reserved. 0899-823X/2014/3508-0001\$15.00. DOI: 10.1086/677144 
B. Both VAP and VAC extend patients' duration of mechanical ventilation, increase intensive care and hospital length of stay, and increase mortality risk. ${ }^{11,14-16,20,21}$ They are also associated with increased use of antimicrobials. ${ }^{12}$

C. VAP increases direct medical costs. ${ }^{21}$ Excess costs attributable to VAC have not been quantified.

\section{SECTION 2: BACKGROUND-STRATEGIES}

\section{TO DETECT VAP AND OTHER VAES}

I. Despite VAP's clinical importance, our ability to conduct accurate VAP surveillance is very limited.

A. VAP is usually defined by clinical, radiographic, and microbiological criteria. These signs are neither sensitive nor specific relative to histopathology. ${ }^{22-25}$ These criteria are also very subjective, leading to substantial interobserver variability. ${ }^{\mathbf{8 9 , 2 6 - 2 9}}$ Administrative data are similarly inaccurate. ${ }^{7,30-32}$ Improvements in VAP rates do not reliably correlate with improvements in outcomes. ${ }^{33,34}$

1. The weaknesses of traditional VAP surveillance definitions limit their utility for measuring the impact of care improvement programs and for benchmarking quality of care between different healthcare facilities. $^{35-38}$

II. CDC's VAE framework

A. The CDC convened representatives from critical and respiratory care, infectious diseases, healthcare epidemiology, and infection prevention professional societies in 2011-2012 to develop a new approach to surveillance for mechanically ventilated patients in an attempt to overcome some of the limitations of traditional VAP surveillance definitions. ${ }^{39}$

1. The working group recommended the following:

a. Developing new definitions based on objective, quantitative criteria to increase the reliability, reproducibility, comparability, and efficiency of surveillance.

b. Broadening the focus of surveillance from pneumonia alone to complications of mechanical ventilation in general. This simultaneously sidesteps VAP definitions' poor specificity and emphasizes the importance of preventing all complications of mechanical ventilation, not just pneumonia.

2. The $C D C$ and the working group utilized emerging research on objective surveillance definitions to develop VAE definitions for adults. ${ }^{10-13,40,41}$

a. Objective definitions predicated on sustained increases in ventilator settings after a period of stability detect a range of clinically significant events, including VAP, pulmonary edema, acute respiratory distress syndrome, and atelectasis. ${ }^{10,12}$ They consistently predict poor patient outcomes, including prolonged mechanical ventilation, increased length of stay in both the intensive care unit (ICU) and the hospital, and increased hospital mortality. ${ }^{10-13}$ Early data suggest that VACs may be preventable. ${ }^{14,42}$ Surveillance using these definitions is efficient and potentially automatable. . $^{10,11,15}$

b. The VAE surveillance framework includes 3 definition tiers. These definitions are briefly summarized below, but readers are advised to consult the CDC's surveillance protocol for comprehensive details. $^{43}$

$i$. VACs

(a) VAC is defined by greater than or equal to 2 days of stable or decreasing daily minimum positive end expiratory pressure (PEEP) or daily minimum fraction of inspired oxygen $\left(\mathrm{FiO}_{2}\right)$ followed by an increase in daily minimum PEEP greater than or equal to $3 \mathrm{~cm}$ of $\mathrm{H}_{2} \mathrm{O}$ or daily minimum $\mathrm{FiO}_{2}$ greater than or equal to 0.20 points sustained for greater than or equal to 2 calendar days.

ii. IVACs

(a) IVAC is triggered by the presence of possible infection indicators concurrent with VAC onset, namely, an abnormal temperature (below $36^{\circ} \mathrm{C}$ or above $38^{\circ} \mathrm{C}$ ) or white blood cell count (less than or equal to 4,000 or greater than or equal to $12,000 \mathrm{cells} / \mathrm{mm}^{3}$ ) and 1 or more new antibiotic starts that continue for greater than or equal to 4 days.

iii. Possible VAP and probable VAP

(a) Possible VAP is defined as Gram stain evidence of purulent pulmonary secretions or a pathogenic pulmonary culture in a patient with IVAC. Probable VAP is defined as Gram stain evidence of purulence plus quantitative or semiquantitative growth of a pathogenic organism beyond specified thresholds. Probable VAP can also be triggered by positive tests for respiratory viruses, Legionella species, pleural fluid cultures, and suggestive histopathology with or without an abnormal Gram stain result.

iv. VAC and IVAC were developed to be appropriate for public reporting; however, further evidence is needed of their preventability and comparability between institutions before recommending their adoption for public reporting or benchmarking.

v. Possible and probable VAP were developed for healthcare facilities to use for internal quality improvement purposes only. They are not suitable for public reporting or benchmarking because clinicians and hospitals vary widely in when and how they acquire and process pulmonary specimens from ventilated patients. 
vi. VAE definitions were designed for adult patients. More data are needed to inform whether and how VAE can be adapted for surveillance in children and neonates.

III. Recommended surveillance strategies

A. Hospitals are advised to conduct active surveillance for VAE, using $C D C$ definitions and surveillance protocols. ${ }^{43}$ The CDC's VAE module requires surveillance for all definition tiers (VAC, IVAC, possible VAP, and probable VAP).

1. Infection preventionists should work with their critical care, respiratory therapy, and/or information technology staff to develop efficient means to gather and aggregate ventilator data (daily minimum PEEP and daily minimum $\mathrm{FiO}_{2}$ ) from all patients ventilated for greater than or equal to 4 days. Temperature, white blood cell count, and antibiotic exposure data are needed only for the subset of patients who fulfill VAC criteria to determine if they fulfill IVAC criteria. Pulmonary specimen Gram stains and microbiology test results are required only for the subset of patients who meet IVAC criteria to determine if they fulfill possible or probable VAP criteria.

2. Organizing daily ventilator data into "line lists" for every patient, with 1 row of data per patient per calendar day, facilitates VAC detection by allowing the surveyor to vertically scan daily ventilator settings to look for sustained increases that cross the threshold for VAC. ${ }^{44}$ Surveyors can also enter raw data into the $\mathrm{CDC}$ 's online "VAE calculator" to assist with case identification (http://www.cdc.gov/nhsn/VAE-calculator /index.html).

a. The VAE definitions are amenable to partial or complete automation using electronic data. Facilities seeking to automate VAE detection should work with their information technology personnel and/or electronic health record vendor(s).

\section{SECTION 3: BACKGROUND-STRATEGIES}

\section{TO PREVENT VAP AND OTHER VAES}

I. Framework for evaluating and prioritizing interventions

A. Although VAE is now the CDC's recommended surveillance metric for ventilated patients, almost all of the existing literature on VAP prevention is based on traditional VAP definitions rather than VAE definitions. There are no data at present on the impact of traditional VAP prevention strategies on "probable pneumonias" (the closest proxy for VAP in the VAE framework), and there are very little data regarding their impact on VAC and IVAC. ${ }^{14,45}$ Of note, VAC and IVAC intentionally flag more than just pneumonia; hence, interventions directed solely against pneumonia may not be sufficient to reduce VAE rates.

B. VAC may be a surveillance marker for nosocomial acute lung injury. Qualitative analyses suggest that most VACs are due to pneumonia, pulmonary edema, atelectasis, and acute respiratory distress syndrome. ${ }^{10,12,15}$ Interventions that target these complications in particular and interventions designed to shorten the duration of mechanical ventilation in general may therefore be effective strategies to lower VAE rates. These could include minimizing the use of sedatives, paired daily spontaneous awakening and breathing trials, early mobility, endotracheal tubes with subglottic secretion drainage ports, low tidal volume ventilation, intermittent recruitment maneuvers, conservative fluid management, and restrictive transfusion thresholds. ${ }^{46-54}$ Studies evaluating the impact of these and other interventions on VAE rates are needed.

C. Until studies of the best strategies to prevent all VAEs are published, the existing VAP prevention literature is the best available guide to improving outcomes for ventilated patients. Given the uncertainty surrounding the accuracy and reproducibility of VAP diagnoses, however, we prioritize VAP interventions that have been shown to improve objective outcomes, such as duration of mechanical ventilation, intensive care or hospital length of stay, mortality, and/or costs in randomized controlled trials. In addition, the potential benefits of different interventions are balanced against their feasibility, costs, and potential harm. Recent reviews using this framework informed our recommendations. $^{33,34,55,56}$

\section{SECTION 4: RECOMMENDATIONS FOR PREVENTION OF VAP AND OTHER VAES}

Interventions that improve objective outcomes with little risk of harm are classified as basic practices that are suitable for all hospitals. We also recommend interventions that are outcome neutral but cost saving. Interventions that improve objective outcomes but carry some risk of harm and interventions that lower VAP rates but for which insufficient data exist to determine their impact on objective outcomes are classified as special approaches. Hospitals can consider adopting special approaches if their VAE rates do not improve despite high performance rates on basic practices. Interventions that improve neither VAP rates nor objective outcomes are not recommended. The quality-of-evidence rating scheme is summarized in Table 1. Recommended strategies are summarized in Table 2 for adults, in Table 3 for preterm neonates, and in Table 4 for infants and children.

\section{Adult Patients}

I. Basic practices to prevent VAP and other VAEs in adult patients: interventions with little risk of harm that decrease duration of mechanical ventilation, length of stay, mortality, and/or costs 
TABLE 1. Grading of the Quality of Evidence

Grade
I. High
Highly confident that the true effect lies close to that of the estimated size and direction of the
effect. Evidence is rated as high quality when there is a wide range of studies with no major
limitations, there is little variation between studies, and the summary estimate has a narrow
confidence interval.
The true effect is likely to be close to the estimated size and direction of the effect, but there is
a possibility that it is substantially different. Evidence is rated as moderate quality when there
are only a few studies and some have limitations but not major flaws, there is some variation
between studies, or the confidence interval of the summary estimate is wide.
The true effect may be substantially different from the estimated size and direction of the effect.
Evidence is rated as low quality when supporting studies have major flaws, there is important
variation between studies, the confidence interval of the summary estimate is very wide, or
there are no rigorous studies, only expert consensus.

NOTE. Based on Grades of Recommendation, Assessment, Development, and Evaluation (GRADE) (39 $^{23}$ and the Canadian Task Force on Preventive Health Care. ${ }^{240}$

A. Avoid intubation if possible

1. Use noninvasive positive pressure ventilation (NIPPV) whenever feasible (quality of evidence: I).

a. NIPPV can be beneficial for patients with acute hypercarbic or hypoxemic respiratory failure secondary to chronic obstructive pulmonary disease or cardiogenic congestive heart failure. ${ }^{57-59}$ NIPPV for these indications may decrease VAP risk, shorten the duration of mechanical ventilation, decrease length of stay, and lower mortality rates compared with invasive ventilation. Use caution when considering NIPPV to manage impaired consciousness, acute lung injury, acute respiratory distress syndrome, severe hypoxemia, and severe acidemia or when continuing NIPPV for patients whose dyspnea or gas exchange fails to rapidly respond to NIPPV. Use of NIPPV for these indications may delay intubation and increase harm, including death..$^{59,60}$

B. Minimize sedation

1. Manage ventilated patients without sedatives whenever possible (quality of evidence: II). ${ }^{46}$

a. Preferentially use agents and strategies other than benzodiazepines to manage agitation, such as analgesics for patients in pain, reassurance, antipsychotics, dexmedetomidine, and propofol..$^{61}$

2. Interrupt sedation once a day (spontaneous awakening trials) for patients without contraindications (quality of evidence: I) ${ }^{62,63}$

a. Two randomized controlled trials found that daily sedative interruptions decreased net sedative exposures and reduced the average duration of mechanical ventilation by $2-4$ days. ${ }^{48,62} \mathrm{~A}$ third trial found no impact on duration of mechanical ventilation but used substantially higher doses of benzodiazepines compared with the first 2 trials and observed an increase in sedative use in the sedation-interruption group. ${ }^{64}$ These factors may have mitigated the potential benefits of sedative interruption in this trial. ${ }^{65}$

3. Assess readiness to extubate once a day (spontaneous breathing trials) in patients without contraindications (quality of evidence: I) ${ }^{47,66-68}$

a. Daily spontaneous breathing trials are associated with extubation 1-2 days earlier compared with usual care. ${ }^{47,69}$

4. Pair spontaneous breathing trials with spontaneous awakening trials (quality of evidence: I) ${ }^{48}$

a. Patients are more likely to pass a spontaneous breathing trial and be extubated if they are maximally awake at the time of the breathing trial.

C. Maintain and improve physical conditioning

1. Provide early exercise and mobilization (quality of evidence: II).

a. Early exercise and mobilization speed extubation, decrease length of stay, and increase the rate of return to independent function. ${ }^{49,70-77}$

b. Financial modeling suggests that early mobility programs may be cost saving. ${ }^{78}$

D. Minimize pooling of secretions above the endotracheal tube cuff

1. Provide endotracheal tubes with subglottic secretion drainage ports for patients likely to require greater than 48 or 72 hours of intubation (quality of evidence: II).

a. Intermittent and continuous drainage of subglottic secretions has been studied in 13 randomized controlled trials. On meta-analysis, the use of endotracheal tubes with subglottic drainage reduced VAP rates by $55 \%$, mean duration of mechanical ventilation by 1.1 days, and intensive care length of stay by 1.5 days. ${ }^{50}$ There was no impact on hospital length of stay or mortality. One study found that subglottic secretion drainage was associated with less antibiotic utilization, while a second did not. ${ }^{79,80}$

b. Endotracheal tubes with subglottic secretion drainage may be cost saving. ${ }^{81,82}$ 
c. Reductions in duration of mechanical ventilation with subglottic secretion drainage appear to be limited to patients expected to require greater than 48-72 hours of mechanical ventilation. ${ }^{83}$ Endotracheal tubes with subglottic secretion drainage ports are therefore recommended only as a basic practice for patients likely to require greater than $48-72$ hours of intubation. Identifying these patients in advance can be very difficult. Patients requiring emergency intubation in the hospital and preoperative patients at risk for prolonged mechanical ventilation are reasonable candidates.

d. Extubating patients to place a subglottic secretion drainage endotracheal tube is not recommended.

E. Elevate the head of the bed

1. Elevate the head of the bed to $30^{\circ}-45^{\circ}$ (quality of evidence: III).

a. Elevating the head of the bed has been evaluated in only 3 randomized controlled trials enrolling 337 patients altogether. ${ }^{84-86}$ One trial reported a $76 \%$ decrease in VAP rates, whereas the other 2 found no difference in VAP rates. Of note, the larger of the 2 negative studies achieved minimal difference in head-of-bed elevation between the intervention and control groups, thereby limiting this study's capacity to evaluate the effect of head-of-bed elevation on VAP or other outcomes. ${ }^{85}$ Nonetheless, a meta-analysis pooling these 3 studies did find a significant impact on $\mathrm{VAP}^{87}$ In addition, enteral feeding in the supine position substantially increases the risk of developing VAP ${ }^{84}$

b. There are insufficient data at present to determine the impact of head-of-bed elevation on duration of mechanical ventilation or mortality, but given the simplicity, ubiquity, minimal risk, lack of cost, and potential benefit of this intervention we classify it as a basic practice while we await further data.

F. Maintain ventilator circuits

1. Change the ventilator circuit only if visibly soiled or malfunctioning (quality of evidence: I).

a. Changing the ventilator circuit as needed rather than on a fixed schedule has no impact on VAP rates or patient outcomes but decreases costs. ${ }^{88-91}$

2. Follow $\mathrm{CDC} / \mathrm{Healthcare}$ Infection Control Practices Advisory Committee guidelines for sterilization and disinfection of respiratory care equipment (quality of evidence: II). ${ }^{92}$

II. Special approaches

A. Interventions that decrease duration of mechanical ventilation, length of stay, and/or mortality but for which insufficient data on possible risks are available

1. Use selective decontamination of the oropharynx to decrease the microbial burden of the aerodigestive tract (quality of evidence: I). ${ }^{93-98}$ a. Selective decontamination of the oropharynx with topical antibiotics or of the oropharynx and digestive tract with a combination of topic, oral, and parenteral antibiotics decreased mortality rates by $14 \%$ and $17 \%$, respectively, in a large cluster randomized trial conducted in the Netherlands. ${ }^{95}$

b. This strategy has not yet been adopted by North American centers, however, due to fear that it might increase the risk of antibiotic-resistant infections, including Clostridium difficile infections, especially in centers with high baseline rates of antimicrobial-resistant organisms. Most studies to date do not indicate an elevated short-term risk for antimicrobial resistance, but long-term studies are lacking. ${ }^{99,100}$ Hospitals with high baseline rates of antibiotic resistance are advised to await the results of long-term studies of digestive decontamination in high-resistance environments before routinely adopting this strategy.

B. Interventions that may lower VAP rates but for which there are insufficient data at present to determine their impact on duration of mechanical ventilation, length of stay, and mortality

1. Perform oral care with chlorhexidine (quality of evidence: II).

a. Oral care with chlorhexidine has been studied in at least 16 randomized controlled trials and 9 metaanalyses to date..$^{98,101-108}$ The benefits of oral care with chlorhexidine appear to be most pronounced in preventing postoperative respiratory tract infections in cardiac-surgery patients. ${ }^{108-110}$ The data for non-cardiac-surgery patients are more equivocal. Meta-analyses suggest that oral care with chlorhexidine can reduce pneumonia rates in this population by $10 \%-30 \%$; however, there is no apparent impact on average duration of mechanical ventilation, intensive care length of stay, or mortality. ${ }^{98,101,102,108}$

b. Routine oral care without chlorhexidine may be indicated for reasons other than VAP prevention.

2. Administer prophylactic probiotics (quality of evidence: II).

a. Four meta-analyses of randomized controlled trials have found an association between probiotics and lower VAP rates. ${ }^{111-114}$ Three of the meta-analyses reported on length of stay and mortality. Two found a positive impact on intensive care length of stay, while the third did not. ${ }^{11,112,114}$ None detected a significant impact on mortality rates. Probiotics should not be used in patients with compromised immune systems or gastrointestinal diseases that increase the risk of gut translocation. There are multiple case reports of fungemia or bacteremia in patients administered probiotics and case reports of aerosol transmission of probiotics within ICUs. ${ }^{115-119}$ 
TABLE 2. Summary of Recommendations for Preventing Ventilator-Associated Pneumonia (VAP) in Adult Patients

\begin{tabular}{|c|c|c|c|}
\hline Recommendation & Rationale & Intervention & $\begin{array}{l}\text { Quality of } \\
\text { evidence }\end{array}$ \\
\hline \multirow[t]{9}{*}{ Basic practices } & \multirow{9}{*}{$\begin{array}{l}\text { Good evidence that the intervention } \\
\text { decreases the average duration of } \\
\text { mechanical ventilation, length of } \\
\text { stay, mortality, and/or costs; benefits } \\
\text { likely outweigh risks }\end{array}$} & $\begin{array}{l}\text { Use noninvasive positive pressure ventilation in } \\
\text { selected populations } s^{57,58}\end{array}$ & High \\
\hline & & Manage patients without sedation whenever possible ${ }^{46,61}$ & Moderate \\
\hline & & Interrupt sedation daily ${ }^{62}$ & High \\
\hline & & Assess readiness to extubate daily ${ }^{47,66-68}$ & High \\
\hline & & $\begin{array}{l}\text { Perform spontaneous breathing trials with sedatives } \\
\text { turned off }\end{array}$ & High \\
\hline & & Facilitate early mobility ${ }^{49,70-75,78}$ & Moderate \\
\hline & & $\begin{array}{l}\text { Utilize endotracheal tubes with subglottic secretion } \\
\text { drainage ports for patients expected to require greater } \\
\text { than } 48 \text { or } 72 \text { hours of mechanical ventilation }{ }^{50}\end{array}$ & Moderate \\
\hline & & $\begin{array}{l}\text { Change the ventilator circuit only if visibly soiled or } \\
\text { malfunctioning }\end{array}$ & High \\
\hline & & Elevate the head of the bed to $30^{\circ}-45^{\circ 84-86}$ & Low $^{a}$ \\
\hline \multirow[t]{7}{*}{ Special approaches } & $\begin{array}{l}\text { Good evidence that the intervention } \\
\text { improves outcomes but insufficient } \\
\text { data available on possible risks }\end{array}$ & Selective oral or digestive decontamination ${ }^{93-96}$ & High $^{\mathrm{b}}$ \\
\hline & \multirow{6}{*}{$\begin{array}{l}\text { May lower VAP rates but insufficient } \\
\text { data to determine impact on dura- } \\
\text { tion of mechanical ventilation, length } \\
\text { of stay, or mortality }\end{array}$} & Regular oral care with chlorhexidine $e^{98,101-104}$ & Moderate \\
\hline & & Prophylactic probiotics ${ }^{111-114}$ & Moderate \\
\hline & & Ultrathin polyurethane endotracheal tube cuffs ${ }^{120,121}$ & Low \\
\hline & & $\begin{array}{l}\text { Automated control of endotracheal tube cuff } \\
\text { pressure }^{122,123}\end{array}$ & Low \\
\hline & & Saline instillation before tracheal suctioning ${ }^{124}$ & Low \\
\hline & & Mechanical tooth brushing ${ }^{125,126}$ & Low \\
\hline \multirow{7}{*}{$\begin{array}{l}\text { Generally not } \\
\text { recommended }\end{array}$} & Lowers VAP rates but ample data sug- & Silver-coated endotracheal tubes ${ }^{127}$ & Moderate \\
\hline & gest no impact on duration of me- & Kinetic beds ${ }^{128}$ & Moderate \\
\hline & $\begin{array}{l}\text { chanical ventilation, length of stay, } \\
\text { or mortality }\end{array}$ & Prone positioning ${ }^{87,129-134, \mathrm{c}}$ & Moderate \\
\hline & \multirow{4}{*}{$\begin{array}{l}\text { No impact on VAP rates, average dura- } \\
\text { tion of mechanical ventilation, length } \\
\text { of stay, or mortality }\end{array}$} & Stress ulcer prophylaxis ${ }^{135,136}$ & Moderate \\
\hline & & Early tracheotomy ${ }^{137}$ & High \\
\hline & & Monitoring residual gastric volumes ${ }^{138}$ & Moderate \\
\hline & & Early parenteral nutrition ${ }^{139}$ & Moderate \\
\hline No recommendation & $\begin{array}{l}\text { No impact on VAP rates or other pa- } \\
\text { tient outcomes, unclear impact on } \\
\text { costs }\end{array}$ & Closed/in-line endotracheal suctioning ${ }^{141-143}$ & Moderate \\
\hline
\end{tabular}

\footnotetext{
a There are very little data on head-of-bed elevation, but it is classified as a basic practice because of its simplicity, ubiquity, low cost, and potential benefit.

$\mathrm{b}$ There are abundant data on the benefits of digestive decontamination but insufficient data on the long-term impact of this strategy on antimicrobial resistance rates.

c May be indicated for reasons other than VAP prevention.
}

3. Use ultrathin polyurethane endotracheal tube cuffs (quality of evidence: III).

a. Ultrathin polyurethane cuffs seal more uniformly against the tracheal wall and may therefore allow fewer secretions to seep around the cuff and into the lungs. Two studies reported lower VAP rates but were underpowered to assess other outcomes. ${ }^{120,121}$

4. Provide automated control of endotracheal tube cuff pressure (quality of evidence: III).

a. Automated control of endotracheal tube cuff pressure led to lower VAP rates in one trial but not in another. ${ }^{122,123}$ Neither trial detected an impact on duration of mechanical ventilation, length of stay, or mortality.

5. Instill saline before tracheal suctioning (quality of evidence: III). 
a. One randomized trial in oncology patients found that saline instillation before tracheal suctioning lowered the rate of microbiologically confirmed VAP but had no impact on clinical VAP rates or patient outcomes. ${ }^{124}$

6. Provide mechanical tooth brushing (quality of evidence: III).

a. One small randomized controlled trial suggested that tooth brushing can lower VAP rates, but a metaanalysis of 4 trials did not detect a significant impact on VAP risk, duration of mechanical ventilation, intensive care length of stay, or mortality. ${ }^{125,126}$

III. Approaches that are generally not recommended for routine VAP prevention

A. Generally not recommended for VAP prevention: interventions that may lower VAP rates but good-quality evidence suggests no impact on duration of mechanical ventilation, length of stay, or mortality

1. Silver-coated endotracheal tubes (quality of evidence: II).

a. A large, multicenter randomized controlled trial found that silver-coated endotracheal tubes reduced VAP rates by $36 \%$ but found no impact on mean duration of mechanical ventilation, hospital length of stay, or mortality. ${ }^{127}$

2. Kinetic beds (continuous lateral rotational therapy and oscillation therapy; quality of evidence: II).

a. A meta-analysis of 15 randomized controlled trials found a significant decrease in VAP rates but no impact on duration of mechanical ventilation or mortality. ${ }^{128}$ The meta-analysis authors warned that the observed reduction in VAP rates might be artifactual given weaknesses in contributing studies' design and execution.

3. Prone positioning (quality of evidence: II).

a. Placing patients in the prone position is controversial. Most meta-analyses suggest a borderline effect on VAP rates and no impact on objective outcomes, except among patients with severe acute respiratory distress syndrome. ${ }^{87,129-134}$

B. Definitively not recommended for VAP prevention: interventions with good-quality evidence suggesting that they neither lower VAP rates nor decrease duration of mechanical ventilation, length of stay, or mortality.

1. Stress ulcer prophylaxis (quality of evidence: II).

a. Stress ulcer prophylaxis lowers the risk of gastrointestinal bleeding, but meta-analyses suggest that there is no impact on nosocomial pneumonia rates, length of stay, or mortality. ${ }^{135,136}$ Effects may differ in patients receiving enteral nutrition: gastrointestinal bleeding is less likely, and stress ulcer prophylaxis may increase the risk of nosocomial pneumonia and mortality. ${ }^{135}$

b. Stress ulcer prophylaxis may be indicated for reasons other than VAP prevention.
2. Early tracheotomy (quality of evidence: I).

a. Early versus late tracheotomy had no impact on VAP rates, duration of mechanical ventilation, or mortality risk on meta-analysis of 7 randomized controlled trials. ${ }^{137}$

3. Monitoring residual gastric volumes (quality of evidence: II).

a. Monitoring patients for regurgitation and vomiting alone is as effective as monitoring patients for regurgitation, vomiting, and residual gastric volumes with regard to VAP rates, duration of mechanical ventilation, and mortality. ${ }^{138}$

4. Early parenteral nutrition (quality of evidence: II).

a. Initiation of parenteral nutrition in critically ill patients within 48 hours of ICU admission is associated with an increased risk of nosocomial infections and mortality compared with initiating parenteral nutrition on or after 8 days. ${ }^{139}$

IV. Approaches that are neither recommended nor discouraged

A. Interventions with no impact on VAP rates or patient outcomes and unclear impact on costs

1. Closed endotracheal tube suctioning systems (quality of evidence: II).

a. Meta-analyses have found no difference in VAP rates, duration of mechanical ventilation, intensive care length of stay, or mortality between patients randomized to open versus closed endotracheal suctioning systems. ${ }^{140-142} \mathrm{~A}$ crossover trial in 4 ICUs found no difference between open versus closed systems in patient-to-patient transmissions of gramnegative pathogens. ${ }^{143}$ Different trials have reached different conclusions regarding cost. ${ }^{141,144,145}$

\section{Neonatal Patients}

Framework for evaluating and prioritizing interventions. Very few studies in neonates evaluate the impact of VAP prevention interventions on duration of mechanical ventilation, length of stay, or mortality. We therefore evaluated potential interventions solely on the basis of safety, feasibility, and potential impact on VAP rates. Interventions that lower VAP rates and confer minimal risks of harm are classified as basic practices. Interventions with unproven but potential impact on VAP rates and minimal risk of harm are classified as special approaches. Hospitals can consider special approaches if their VAP rates do not improve despite high performance rates for basic practices. Interventions with unknown benefits, known risks of harm, or unknown risks of harm are not recommended.

Specific considerations in preterm neonates. Clinical signs used to diagnose VAP in adults have limited utility in preterm neonates. Fever rarely occurs in preterm neonates, since they are prone to hypothermia and are therefore often thermoregulated with incubators or radiant heaters. Worsening gas exchange or apnea can be caused by significant nonpulmon- 
TABLE 3. Summary of Recommendations for Preventing Ventilator-Associated Pneumonia (VAP) in Preterm Neonates

\begin{tabular}{|c|c|c|c|}
\hline Recommendation & Rationale & Intervention & $\begin{array}{l}\text { Quality of } \\
\text { evidence }\end{array}$ \\
\hline Basic practices & $\begin{array}{l}\text { May lower VAP rates and minimal } \\
\text { risks of harm; benefits likely out- } \\
\text { weigh potential risks }\end{array}$ & $\begin{array}{l}\text { Use noninvasive positive pressure ventilation in } \\
\text { selected populations } \\
\text { Minimize the duration of mechanical ventilation } \\
\text { Assess readiness to extubate daily } \\
\text { Manage patients without sedation whenever } \\
\text { possible } \\
\text { Avoid unplanned extubation }{ }^{152} \\
\text { Provide regular oral care with sterile water } \\
\text { Minimize breaks in the ventilator circuit } \\
\text { Change the ventilator circuit only if visibly soiled or } \\
\text { malfunctioning }\end{array}$ & $\begin{array}{l}\text { High } \\
\text { High } \\
\text { Low } \\
\text { Low } \\
\text { Low } \\
\text { Low } \\
\text { Low } \\
\text { Low }\end{array}$ \\
\hline Special approaches & $\begin{array}{l}\text { Unknown impact on VAP rates, but } \\
\text { risk of harm likely minimal; reason- } \\
\text { able to consider implementing if } \\
\text { rates remain elevated despite basic } \\
\text { practices }\end{array}$ & $\begin{array}{l}\text { Lateral recumbent positioning }{ }^{155} \\
\text { Reverse Trendelenburg positioning } \\
\text { Closed/in-line suctioning systems }{ }^{156,157}\end{array}$ & $\begin{array}{l}\text { Low } \\
\text { Low } \\
\text { Low }\end{array}$ \\
\hline \multirow[t]{3}{*}{$\begin{array}{l}\text { Generally not } \\
\text { recommended }\end{array}$} & $\begin{array}{l}\text { Unknown impact on VAP rates and in- } \\
\text { adequate data on risks }\end{array}$ & Regular oral care with antiseptics & Low \\
\hline & $\begin{array}{l}\text { May be harmful; risk-benefit balance } \\
\text { does not favor intervention unless } \\
\text { specifically indicated for reasons } \\
\text { other than VAP prevention }\end{array}$ & $\begin{array}{l}\text { Histamine } 2 \text { receptor antagonists } \\
\text { Prophylactic broad-spectrum antibiotics } \\
\text { Daily spontaneous breathing trials } \\
\text { Daily sedative interruptions }\end{array}$ & $\begin{array}{l}\text { Moderate } \\
\text { Moderate } \\
\text { Low } \\
\text { Low }\end{array}$ \\
\hline & $\begin{array}{l}\text { Not recommended because appropriate } \\
\text { products are not available or ap- } \\
\text { proved for use in this population }\end{array}$ & $\begin{array}{l}\text { Prophylactic probiotics or synbiotics }{ }^{167,168} \\
\text { Endotracheal tubes with subglottic secretion drainage } \\
\text { ports } \\
\text { Silver-coated endotracheal tubes }\end{array}$ & $\begin{array}{l}\text { Low } \\
\text { NA } \\
\text { NA }\end{array}$ \\
\hline
\end{tabular}

NOTE. NA, none available.

ary illnesses, including sepsis and necrotizing enterocolitis. New or progressive infiltrates often indicate progression of chronic lung disease rather than new infection.

Pooled mean VAP rates for neonates reported to the CDC's National Healthcare Safety Network (NHSN) vary from 0.2 to 1.8 infections per 1,000 ventilator days. ${ }^{146}$ It is not known whether these rates are broadly representative of all neonatal units, however, since many hospitals do not perform VAP surveillance for neonates in light of the limitations of VAP definitions.

The CDC has not yet developed VAE definitions for neonates. Adult VAE definitions are not suitable for neonates, as they do not reflect standard ventilator management practices for this population.

I. Basic practices for preterm neonates: interventions with minimal risk of harm that may lower VAP rates

A. Avoid intubation if possible

1. Consider nasal continuous positive airway pressure ventilation with or without nasal intermittent mechanical ventilation as an alternative to intubation (quality of evidence: I). ${ }^{147-149}$ a. Many premature neonates can be successfully supported with NIPPV.

B. Minimize the duration of mechanical ventilation

1. Manage patients without sedation whenever possible (quality of evidence: III). ${ }^{150,151}$

2. Assess readiness to extubate daily (quality of evidence: III).

3. Avoid unplanned extubations and reintubations (quality of evidence: III). ${ }^{152}$

4. Provide regular oral care with sterile water (extrapolated from studies in adults, no data in preterm neonates; quality of evidence: III).

5. Minimize breaks in the ventilator circuit (extrapolated from studies in adults, no data in preterm neonates; quality of evidence: III).

6. Change the ventilator circuit only if visibly soiled or malfunctioning (extrapolated from studies in adults and children, no data in preterm neonates; quality of evidence: III). ${ }^{153,154}$

II. Special approaches for preterm neonates

A. Interventions with minimal risks of harm but unknown 
impact on VAP rates

1. Lateral recumbent positioning (quality of evidence: III). ${ }^{155}$

2. Reverse Trendelenburg positioning (quality of evidence: III).

3. Closed/in-line suctioning (quality of evidence: III). ${ }^{156,157}$

III. Generally not recommended

A. Inadequate data on risks and unknown impact on VAP rates in preterm neonates

1. Regular oral care with antiseptic (quality of evidence: III).

a. There are insufficient data on the impact of altering neonatal microflora and whether oral antiseptics are absorbed across the oral mucosa of preterm neonates.

B. May be harmful to preterm neonates

1. Histamine $\mathrm{H} 2$-receptor antagonists may increase the risk of nosocomial infection and mortality in preterm neonates (quality of evidence: II). ${ }^{158,159}$

2. Prophylactic broad-spectrum antibiotics are associated with increased risk of necrotizing enterocolitis, prolonged length of stay, and death in premature infants (quality of evidence: II). ${ }^{160-163}$

3. Spontaneous breathing trials (quality of evidence: III).

a. Ventilating preterm neonates with prolonged continuous positive airway pressure alone increases the risk of extubation failure. ${ }^{164-166}$

C. Not applicable to preterm neonates

1. Daily interruption of sedation (quality of evidence: III).

a. Sedation is not routinely required for neonates on mechanical ventilation.

b. There are no data on the impact of interrupting sedatives when sedation is used.

2. Prophylactic probiotics and synbiotics (quality of evidence: III).

a. There are currently no products approved by the US Food and Drug Administration for preterm neonates. Limited data suggest that these may benefit some patients, but there are also multiple case reports of Lactobacillus bacteremia in infants and children following probiotic therapy. ${ }^{167-171}$

3. Endotracheal tubes equipped with subglottic secretion drains; suitably sized products are not commercially available (quality of evidence: none available).

4. Silver-coated endotracheal tubes; suitably sized products are not commercially available (quality of evidence: none available).

\section{Pediatric Patients}

Framework for evaluating and prioritizing interventions. Diagnosing VAP is as challenging in term infants and children as in preterm neonates and adults. The CDC has convened a working group to consider whether modified VAE definitions might be suitable for infants and children.

Risk factors for VAP in infants and children are similar to those of adults. ${ }^{172-176}$ Once they develop teeth, children's oral flora are similar to those of adults. ${ }^{177,178}$

In general, most VAP prevention interventions recommended for adults are presumed to be applicable to infants and children. Some interventions recommended for adults, however, are not available for infants and small children. For example, some specialized endotracheal tubes are available only in larger sizes.

I. Basic practices for pediatric patients: interventions with minimal risk of harm and some data that they lower VAP rates

A. Avoid intubation if possible

1. Use NIPPV in selected populations whenever feasible (quality of evidence: II).

a. Risks of NIPPV in pediatric patients mirror those for adults listed above in section I.A.1.A, with the added issue that pediatric patients often need sedation to tolerate NIPPV. ${ }^{179,180}$

B. Minimize the duration of mechanical ventilation

1. Assess readiness to extubate daily in patients without contraindications (quality of evidence: II). ${ }^{181-183}$

a. A randomized controlled trial in Brazil reported that daily spontaneous breathing trials decreased the mean duration of ventilation. ${ }^{183}$ There is no consensus on the most effective technique for spontaneous breathing trials in pediatric patients. ${ }^{181,184}$

2. Avoid unplanned extubations and reintubations (quality of evidence: III)..$^{185}$

C. Provide regular oral care

1. Provide regular oral care (quality of evidence: III).

a. Two before-after studies of VAP bundles that emphasized oral care found decreases in VAP rates. ${ }^{173,186}$

b. The American Dental Association recommends beginning oral hygiene a few days after birth. ${ }^{187}$ Wipe the gums with a gauze pad after each feeding to remove plaque and residual formula that could harm erupting teeth. When teeth erupt, brush them gently twice a day with a child's size toothbrush and water. Fluoride toothpaste is recommended from 2 years of age onward. After oral hygiene, rinse and suction the mouth. Keep the oral mucosa and lips clean, moist, and intact using sponge-tipped applicators dipped in nonalcohol, nonperoxide mouth rinse. ${ }^{186}$

D. Elevate the head of the bed

1. Elevate the head of the bed unless medically contraindicated (quality of evidence: III).

a. One before-after study of a VAP bundle that in- 


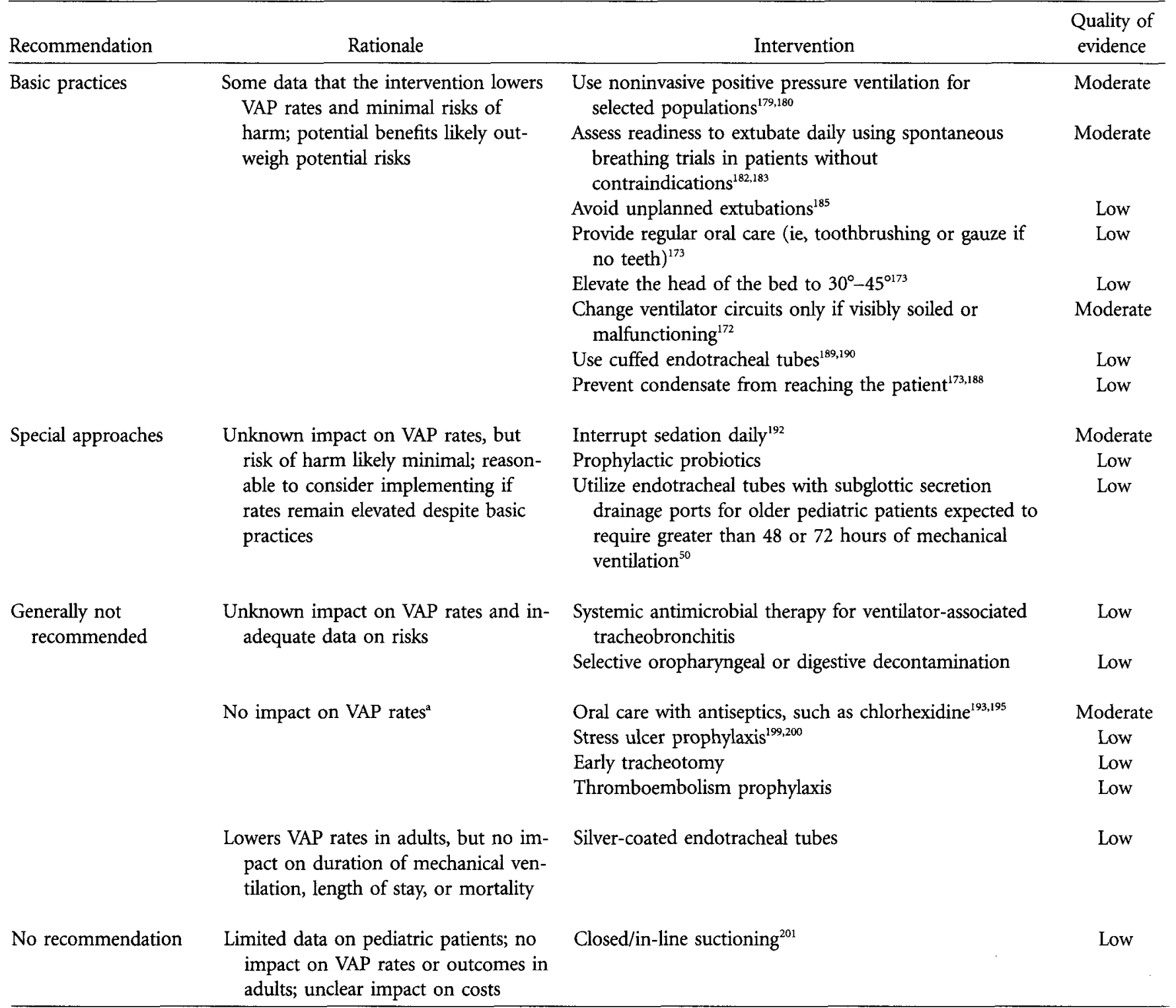

${ }^{a}$ May, however, be indicated for reasons other than VAP prevention.

cluded head-of-bed elevation observed a decrease in VAP rates. ${ }^{173}$

b. Many hospital cribs do not have inbuilt angle-measuring devices. Alternative measuring devices are required in these circumstances.

E. Maintain ventilator circuits

1. Change ventilator circuits only when visibly soiled or malfunctioning (quality of evidence: II).

a. One randomized trial and 1 observational study found no difference in VAP rates or mortality with 3-day versus 7-day circuit changes. Circuit changes are therefore recommended only when the circuit is soiled or malfunctioning, to minimize costs. ${ }^{153,154}$

2. Remove condensate from the ventilator circuit fre- quently (quality of evidence: III).

a. Avoid draining the condensate toward the patient. $^{173}$

3. Suction oral secretions before each position change (quality of evidence: III). ${ }^{188}$

F. Endotracheal tube selection and maintenance

1. Use cuffed endotracheal tubes (quality of evidence: III).

a. Pediatric intensivists have historically favored uncuffed tubes due to concern that cuffs may induce subglottic stenosis in pediatric airways. Cuffing has been proven safe, however, and may decrease the risk of microaspiration. ${ }^{189,190}$ Cuffed tubes are now used routinely for term newborns and children. ${ }^{191}$

2. Maintain cuff pressure and volume at the minimal 
occlusive settings to prevent clinically significant air leaks around the endotracheal tube, typically $20 \mathrm{~cm}$ of water (quality of evidence: III). ${ }^{123,189}$

a. The potential merits of automated manometers for VAP prevention have not been studied in pediatric patients.

II. Special approaches for pediatric patients

A. Interventions with evidence of benefit in adult patients and minimal risks of harm but limited data in pediatric populations

1. Interrupt sedation once a day (quality of evidence: II).

a. Daily sedative interruptions decreased duration of mechanical ventilation and intensive care length of stay without increases in adverse event rates in 1 small randomized controlled trial. ${ }^{192}$

b. There is nonetheless concern that sedative interruptions will increase the frequency of unplanned extubations and reintubations in younger patients, so this practice may be safest in older pediatric patients. More data are needed.

2. Administer prophylactic probiotics (quality of evidence: III).

a. This recommendation is inferred from adult data but should be considered with caution due to sparse safety data in pediatric patients and case reports of Lactobacillus bacteremia associated with probiotic therapy, including cases in children without known immunodeficiency. ${ }^{11-114,169-171}$

3. Use endotracheal tubes with subglottic secretion drainage ports (quality of evidence: III).

a. This intervention is feasible only for children aged greater than or equal to 10 years since the smallest available endotracheal tube with subglottic secretion drainage ports is size 6.0.

III. Generally not recommended for pediatric patients

A. Unknown impact on VAP rates and/or inadequate data on risks

1. Systemic antimicrobial therapy for ventilator-associated tracheobronchitis (quality of evidence: III).

a. One retrospective study found that prolonged antibiotics for tracheobronchitis did not protect against VAP but did increase the prevalence of multidrug-resistant organisms. ${ }^{193}$

2. Selective oropharyngeal or digestive decontamination (quality of evidence: III).

a. See comments in section on adults.

B. No impact on VAP rates (these interventions may, however, be indicated for reasons other than VAP prophylaxis)

1. Oral care with chlorhexidine (quality of evidence: II).

a. Chlorhexidine appears to be safe for developing teeth, ${ }^{194}$ but randomized controlled trials have found no difference in VAP rates, length of stay, or mortality in infants and children. ${ }^{193,195-198}$
2. Stress ulcer prophylaxis (quality of evidence: III).

a. Two small studies found no impact on VAP rates. ${ }^{199,200}$

3. Early tracheotomy (quality of evidence: III).

4. Thromboembolism prophylaxis (quality of evidence: III).

C. Lowers VAP rates but no impact on duration of mechanical ventilation, length of stay, or mortality

1. Silver-coated endotracheal tubes (quality of evidence: III).

IV. No recommendation: limited data from pediatric studies, no impact on VAP rates or outcomes in adults, unclear impact on costs

A. Closed/in-line suctioning

1. An observational study of open versus closed suctioning in children did not find any difference in VAP rates, length of stay, or mortality, but the significance of these findings are unclear given the lack of blinding and randomization (quality of evidence: III). ${ }^{201}$

\section{SECTION 5: PERFORMANCE MEASURES}

\section{Internal reporting}

A. Regular monitoring and internal reporting of patient outcomes and adherence rates to recommended prevention strategies ("process measures") are important quality improvement strategies.

B. Both outcome and process measure reporting are likely beneficial: improving outcomes is the primary goal of care improvement programs, but analyzing performance rates for key processes of care may help identify specific processes to target for improvement.

C. Report process and outcome measures to key organizational stakeholders, including frontline care providers, respiratory therapy directors, nursing and medical leaders, and senior hospital administrators. Feeding these data back to providers and leaders has been associated with improvements in both performance rates and outcomes. ${ }^{202-207}$

D. Report process measures internally only. External reporting of process measure data is not appropriate at this time given substantial variability in the ways different organizations define, collect, analyze, and present process measure data.

E. There are insufficient data at present to guide the definition and implementation of process measures for the prevention of VAP in neonatal and pediatric units.

II. Process measures

A. Process measure definitions and measurement strategies vary widely

1. For organizations that collect and report process measures, clearly define measures, including data sources, inclusion and exclusion criteria, frequency of monitoring, and numerator and denominator criteria.

2. Develop a formal system to document compliance. 
a. Compliance can be measured via direct observations or via audits of patient charts, bedside paperwork, and/or electronic medical records. Periodically validate the accuracy of paper and/or electronic documentation.

3. Perform assessments regularly.

a. The optimal frequency of assessments (eg, once daily, twice daily, or weekly) is not known, but the frequency can likely be adjusted on the basis of compliance rates (eg, as compliance improves, less frequent observations may be sufficient).

B. Prevention bundles

1. Consider combining a core set of critical process measures together into a bundle to enhance care. Bundling care processes facilitates implementation by providing a clear, tangible set of expectations to follow. In addition, some care processes may be synergistic.

2. There is no consensus on which care processes to include in a VAP prevention bundle. There is substantial heterogeneity in different hospitals' ventilator bundles. $^{208}$

3. Evidence on the impact of bundles is limited. Many prevention bundles have been associated with variable reductions in VAP rates. A smaller subset has been associated with improvements in objective outcomes. ${ }^{209-214}$ To date, however, prevention bundles have been tested only in observational before-after and time-series analyses rather than in randomized controlled trials. It is therefore difficult to disentangle the extent to which lower VAP rates and better outcomes are due to prevention bundles versus secular trends in severity of illness, advances in medical care, and ascertainment biases.

4. Compliance can be reported for each process measure individually and/or as all-or-none compliance with a bundle of process measures. For all-or-none compliance, credit is given only if all components have been accomplished and documented; if any components were not performed and/or were not documented, no credit is given. ${ }^{212,215}$

III. Approaches to defining process measures

A. There is no consensus on how best to define adherence to different process measures. Examples of how different organizations have defined selected process measures are summarized below. These examples are primarily drawn from multicenter quality improvement initiatives.

1. Optimize hand hygiene

a. Readers are referred to the Compendium article "Strategies to Prevent Healthcare-Associated Infections through Hand Hygiene" ${ }^{\text {"216 }}$ for a comprehensive discussion of this topic.

2. Minimize sedation

a. Perform spontaneous awakening trials daily.

i. Definitions (a) Girard et $\mathrm{al}^{48}$ defined this as the percentage of sedative-days (ventilator-days during which sedatives are administered) on which sedative and analgesic continuous infusions were interrupted or where at least 1 scheduled dose of an intermittently prescribed sedative or analgesic was withheld.

(b) Berenholtz et $\mathrm{al}^{207}$ defined this as the percentage of ventilator-days on which patients prescribed any sedative medications were able to follow commands at least once during the course of the day.

b. Inclusion criteria: all patients on mechanical ventilation being treated with 1 or more of the following drugs: lorazepam, midazolam, propofol, fentanyl, morphine, meperidine, hydromorphone, or dexmedetomidine. ${ }^{207}$

c. Exclusion criteria: patients receiving a sedative infusion for active seizures or alcohol withdrawal, escalating sedative doses due to ongoing agitation, neuromuscular blockade, evidence of active myocardial ischemia within the previous 24 hours, evidence of increased intracranial pressure. ${ }^{48,207}$

3. Expedite extubation

A. Perform spontaneous breathing trials daily

a. Definitions

$i$. Percentage of ventilator-days on which patients received a trial of spontaneous ventilation. A trial of spontaneous breathing is defined as a period of time where ventilatory support is removed. This can be done by allowing the patient to

(a) Breathe through a T-tube circuit

(b) Breathe through a ventilator circuit using "flow triggering" with continuous positive airway pressure of $0-5 \mathrm{~cm}$ of water and/ or pressure support ventilation with 5-8 $\mathrm{cm}$ of water. ${ }^{48,207,217}$

ii. The initial spontaneous breathing trial should last at least 30 minutes.

b. Inclusion criteria: all patients on mechanical ventilation.

c. Exclusion criteria: oxygen saturation less than $88 \%, \mathrm{FiO}_{2}$ greater than $50 \%$, PEEP greater than $8 \mathrm{~cm}$ of water, lack of spontaneous breathing effort for greater than or equal to 5 minutes, agitation, active myocardial ischemia, significant vasopressor requirement, increased intracranial pressure, moribund state with death likely imminent. ${ }^{48}$

4. Minimize the risk of aspiration

a. Elevate the head of the bed

i. Definitions

(a) Berenholtz et $\mathrm{al}^{207}$ defined this as the per- 
centage of ventilator-days on which the head of the bed is elevated $30^{\circ}-45^{\circ}$.

(b) Bloos et $\mathrm{al}^{213}$ had access to continuous electronic monitoring of their beds' backrest elevation angles. They therefore defined headof-bed elevation compliance as the mean daily backrest elevation angle.

(c) Sinuff et $\mathrm{al}^{214}$ tracked concordance with head-of-bed elevation to $45^{\circ}$. They defined concordance as the sum of days on which the head of the bed was elevated plus the days on which head-of-bed elevation was contraindicated divided by total ventilatordays. They encouraged providers to consider elevating the head of the bed as much as possible when elevation to $45^{\circ}$ was not possible.

ii. Inclusion criteria: all patients on mechanical ventilation.

iii. Exclusion criteria: patients with hemodynamic instability, undergoing resuscitation, unstable spine or not cleared, pelvic instability or fractures, prone position, intra-aortic balloon pump in femoral vessels, and obesity procedures. ${ }^{214}$

\section{Outcome measures}

A. Conduct surveillance for all VAEs, including VAC, IVAC, possible VAP, and probable VAP in adult ICUs. Report rates for all events included in the algorithm. VAE definitions are not currently available for pediatric and neonatal patients; hence, these units should continue to use traditional NHSN VAP definitions.

\section{VAE incidence density}

a. Numerator: total number of VACs, including IVACs, possible VAPs, and probable VAPs.

b. Denominator: total ventilator-days.

c. Multiply by 1,000 and express as VAEs per 1,000 ventilator-days.

d. Note that the total VAE rate is synonymous with the total VAC rate.

2. IVAC incidence density

a. Numerator: total number of IVACs, including possible VAPs and probable VAPs.

b. Denominator: total ventilator-days.

c. Multiply by 1,000 and express as the IVAC rate per 1,000 ventilator-days.

3. VAP incidence density

a. Organizations can consider calculating both their total VAP rate (sum of possible and probable VAPs) and their probable VAP rate for internal monitoring purposes. The former metric is presumed to be more sensitive, the latter more specific.

b. Total VAP rate

i. Numerator: total number of all possible and probable VAPs.

ii. Denominator: total ventilator-days. iii. Multiply by 1,000 and express as the overall VAP rate per 1,000 ventilator-days.

c. Probable VAP rate

i. Numerator: total number of all probable VAP events.

ii. Denominator: total ventilator-days.

iii. Multiply by 1,000 and express as the probable VAP rate per 1,000 ventilator-days.

V. External reporting

A. VAC and IVAC are potentially appropriate metrics for public reporting, interfacility comparison, and pay-forperformance programs. Better data on their responsiveness to quality improvement programs are necessary, however, before recommending them for interfacility comparisons or pay-for-performance programs. Suitable risk-adjustment strategies are also needed.

B. Possible and probable VAP are not suitable for external reporting at this time since substantial variability in clinical and laboratory practices in the acquisition, processing, and interpretation of culture data preclude meaningful comparisons of VAP rates between institutions.

C. VAP rates generated using NHSN's former surveillance definitions are not appropriate for external reporting in light of their considerable subjectivity.

D. Hospitals in states that have mandatory reporting laws must collect and report data as required by their state. Local and state health departments can provide specific information on public reporting requirements.

\section{SECTION 6: IMPLEMENTATION}

\section{ST RATEGIES}

Accountability is an essential principle for preventing HAIs. It provides the necessary translational link between science and implementation. Without clear accountability, scientifically based implementation strategies will be used in an inconsistent and fragmented way, decreasing their effectiveness in preventing HAIs. Accountability begins with the chief executive officer and other senior leaders who provide the imperative for HAI prevention, thereby making HAI prevention an organizational priority. Senior leadership is accountable for providing adequate resources needed for effective implementation of an HAI prevention program. These resources include necessary personnel (clinical and nonclinical), education, and equipment (Table 5).

Engagement, education, execution, and evaluation are further common attributes of successful care improvement programs. ${ }^{203}$ These attributes are elaborated below.

\section{Engage}

A. Develop a multidisciplinary team

1. Multidisciplinary teams set goals, define each step in the implementation process, and monitor progress in 
TABLE 5. Fundamental Elements of Accountability for Healthcare-Associated Infection Prevention

Senior management is responsible for ensuring that the healthcare system supports an infection prevention and control (IPC) program that effectively prevents healthcare-associated infections (HAIs) and the transmission of epidemiologically important pathogens

Senior management is accountable for ensuring that an adequate number of trained personnel are assigned to the IPC program and adequate staffing of other departments that play a key role in HAI prevention (eg, environmental services)

Senior management is accountable for ensuring that healthcare personnel, including licensed and nonlicensed personnel, are adequately trained and competent to perform their job responsibilities

Direct healthcare providers (such as physicians, nurses, aides, and therapists) and ancillary personnel (such as environmental service and equipment processing personnel) are responsible for ensuring that appropriate IPC practices are used at all times (including hand hygiene, standard and isolation precautions, and cleaning and disinfection of equipment and the environment)

Senior and unit leaders are responsible for holding personnel accountable for their actions

IPC leadership is responsible for ensuring that an active program to identify HAIs is implemented, that HAI data are analyzed and regularly provided to those who can use the information to improve the quality of care (eg, unit staff, clinicians, and hospital administrators), and that evidence-based practices are incorporated into the program

Senior and unit leaders are accountable for ensuring that appropriate training and educational programs to prevent HAIs are developed and provided to personnel, patients, and families

Personnel from the IPC program, the laboratory, and information technology departments are responsible for ensuring that systems are in place to support the surveillance program

reaching goals. ${ }^{173,218,219}$ Programs developed by team consensus are more effective and increase guideline adherence. ${ }^{173,218,220}$ Multidisciplinary teams include representatives from all disciplines that care for ventilated patients, including, at a minimum, unit directors, physicians, nurses, and respiratory therapists. Other partners who can strengthen the team include infection preventionists, pharmacists, nutritionists, physical therapists, occupational therapists, family members, and patient advocates. ${ }^{207,219,221,222}$

B. Involve local champions

1. Identify local champions, including formal (eg, medical director, nursing director, charge nurses, director of respiratory therapy) and informal (eg, engaged frontline staff) leaders. ${ }^{207,213,219,221-223}$

2. Local champions are important to success because they engage stakeholders, educate peers, encourage ongoing improvement, and increase buy-in and ownership by both staff and administrators. ${ }^{173,203,207,220,223,224}$

3. Local champions should know their hospital's interests and needs, be able to shape strategies to match local unit culture, monitor progress, and facilitate necessary changes during implementation. ${ }^{202}$ Early and continual communication between local champions and frontline staff allows providers to ask questions, resolve concerns, prepare for action, and sustain improvements. ${ }^{202,224}$

C. Utilize peer networks

1. Horizontal networking of peers across hospitals can promote and increase compliance with evidence-based best practices. Voluntary peer networks encourage collaboration, analysis of performance, accountability, and commitment to specific goals. ${ }^{207,225-227}$ Comparing progress and benchmarks between ICUs can help units better understand their local strengths and weaknesses, learn from best practices, brainstorm solutions to common problems, and promulgate local successes. ${ }^{227}$

II. Educate

A. Provide education sessions

1. Education sessions help summarize evidence, explain new processes, set expectations, and encourage staff to adopt recommended practices. ${ }^{202,228}$ Education sessions can include workshops, hands-on trainings, conferences, slide presentations, and/or interactive discussions; employing multiple teaching modalities can help meet diverse learning styles. ${ }^{224,229,230}$ Both local champions and topic experts (eg, infection preventionists) can lead staff education. ${ }^{173,226}$

2. Education sessions must be informative and relevant for the learner; therefore, it is important to have multidisciplinary educational programs customized for different specialties. ${ }^{203,204,218}$

3. Ongoing staff education helps maintain high levels of compliance with recommended practices. ${ }^{205,230}$

4. Educating patients and family members may help them better engage with and support the medical team's plan of care.

B. Provide educational materials

1. Provide educational materials to staff that summarize the evidence, support self-study, and remind staff about new practices. ${ }^{231}$ Examples of educational materials include pocket cards, brochures, posters, fact sheets, daily guides, guideline summaries, flow sheets and 1-page bulletins. ${ }^{133,205,207,227,229,232}$

III. Execute

\section{A. Standardize care processes}

1. Standardize care processes through the implementation of guidelines, bundles, protocols, or pathways. Standardization helps establish new care processes as "normal behaviors" for staff. ${ }^{202}$ 
2. Daily multidisciplinary rounds are widely advocated; these rounds should follow a structured format and include discussion about the patients' goals for the day, consideration of what resources and actions are necessary to achieve these goals, and identification of potential barriers and/or safety issues. ${ }^{204,207,222}$

B. Create redundancy

1. Build redundancy or independent checks into caredelivery processes to remind staff about new practices. ${ }^{202,203,212}$ Redundancy can take the form of posters, bulletins, pens, stamps, pocket cards, 1-page signs, daily goals in patient rooms, checklists and preprinted order sets, text messages, and screen savers on clinical computers. ${ }^{203,205,212,226,232-235}$ Encourage family members to ask the care team if patients are receiving evidencebased therapies for VAP prevention. ${ }^{207}$

2. The combination of both education and reminders significantly improves processes of care..$^{228,236}$

IV. Evaluate

\section{A. Measure performance}

1. Measure performance using frequent formal and informal audits of clinical practice. ${ }^{203,237}$

2. Measuring process and outcome measures enhances awareness, establishes expectations, creates urgency, and rewards changes in behavior. ${ }^{202}$

3. Evaluating performance provides an ongoing, realtime image of actual implementation rates. ${ }^{234}$

4. Areas of poor compliance can be rapidly identified and rectified. ${ }^{203,237}$ If compliance remains poor in one area, the improvement team should walk the process with staff to gain additional insights into barriers to implementation. ${ }^{203}$

5. Analyze all or a representative sample of VACs for etiology and preventability. Pneumonia, pulmonary edema, acute respiratory distress syndrome, and atelectasis are typical etiologies for VACs. ${ }^{10,12,15}$ Use your analyses to select and refine prevention strategies that address the most frequent and preventable causes of VACs in your clinical setting.

B. Provide feedback to staff

1. Provide regular feedback on process and/or outcome data to staff. ${ }^{202,204,212,226,235}$ Feedback can be provided via wall displays or during meetings. ${ }^{173,202,229,231}$

2. Providing feedback helps staff appreciate how their efforts to improve are impacting performance rates and patients' outcomes. This helps maintain staff motivation and can boost adherence to new processes. ${ }^{203,238}$

3. Feedback is also important for future efforts because feedback helps pinpoint new areas for improvement and marks successful transitions to new standards of care. . $^{22,203,237,238}$

\section{ACKNOWLEDGMENTS}

Disclaimer. S.S.M.-The findings and conclusions in this report are those of the authors and do not necessarily represent the official position of the Centers for Disease Control and Prevention.

Potential conflicts of interest. M.K. reports having received honoraria for lectures from Premier Healthcare Alliance. L.R.G. reports having received honoraria from Premier, Care Fusion, Infection Control Today, and Advanced Sterilization Products. R.B. reports having served as an advisor/consultant for Covidien, Hamilton, Advanced Circulatory Systems, and Ikaria. E.C.E., M.D.H., G.L., L.L.M., S.S.M., G.P.P., K.S., D.S.Y., and S.M.B. report no conflicts of interest.

Address correspondence to Michael Klompas, MD, MPH, Department of Population Medicine, Harvard Medical School and Harvard Pilgrim Health Care Institute, 133 Brookline Avenue, 6th Floor, Boston, MA 02215 (mklompas@partners.org).

\section{REFERENCES}

1. Coffin SE, Klompas M, Classen D, et al. Strategies to prevent ventilator-associated pneumonia in acute care hospitals. Infect Control Hosp Epidemiol 2008;29(suppl 1):S31-S40.

2. Yokoe DS, Andersen DJ, Berenholtz SM, et al. Introduction to "A Compendium of Strategies to Prevent Healthcare-Associated Infections in Acute Care Hospitals: 2014 Updates." Infect Control Hosp Epidemiol 2014;35(5):455-459.

3. Dudeck MA, Horan TC, Peterson KD, et al. National Healthcare Safety Network (NHSN) report, data summary for 2010, device-associated module. Am J Infect Control 2011;39(10): 798-816.

4. Klompas M. Eight initiatives that misleadingly lower ventilatorassociated pneumonia rates. Am J Infect Control 2012;40(5): $408-410$.

5. Vincent JL, Rello J, Marshall J, et al. International study of the prevalence and outcomes of infection in intensive care units. JAMA 2009;302(21):2323-2329.

6. Magill SS, Hellinger W, Cohen J, et al. Prevalence of healthcareassociated infections in acute care hospitals in Jacksonville, Florida. Infect Control Hosp Epidemiol 2012;33(3):283-291.

7. Thomas BW, Maxwell RA, Dart BW, et al. Errors in administrative-reported ventilator-associated pneumonia rates: are never events really so? Am Surg 2011;77(8):998-1002.

8. Skrupky LP, McConnell K, Dallas J, Kollef MH. A comparison of ventilator-associated pneumonia rates as identified according to the National Healthcare Safety Network and American College of Chest Physicians criteria. Crit Care Med 2012;40(1): 281-284.

9. Novosel TJ, Hodge LA, Weireter LJ, et al. Ventilator-associated pneumonia: depends on your definition. Am Surg 2012;78(8): $851-854$.

10. Klompas M, Khan Y, Kleinman K, et al. Multicenter evaluation of a novel surveillance paradigm for complications of mechanical ventilation. PLoS ONE 2011;6(3):e18062.

11. Klompas M, Magill S, Robicsek A, et al. Objective surveillance definitions for ventilator-associated pneumonia. Crit Care Med 2012;40(12):3154-3161.

12. Hayashi $Y$, Morisawa K, Klompas M, et al. Toward improved surveillance: the impact of ventilator-associated complications on length of stay and antibiotic use in patients in intensive care units. Clin Infect Dis 2013;56(4):471-477. 
13. Prospero E, Illuminati D, Marigliano A, et al. Learning from Galileo: ventilator-associated pneumonia surveillance. $A m J$ Respir Crit Care Med 2012;186(12):1308-1309.

14. Muscedere J, Sinuff $T$, Heyland $D$, et al. The clinical impact and preventability of ventilator-associated conditions in critically ill mechanically ventilated patients. Chest 2013;144(5): 1453-1460.

15. Klein Klouwenberg PM, van Mourik MS, Ong DS, et al. Electronic implementation of a novel surveillance paradigm for ventilator-associated events: feasibility and validation. $\mathrm{Am} \mathrm{J}$ Respir Crit Care Med 2014;189(8):947-955.

16. Klompas M, Kleinman K, Murphy MV. Descriptive epidemiology and attributable morbidity of ventilator-associated events. Infect Control Hosp Epidemiol 2014;35(5):502-510.

17. Nguile-Makao M, Zahar JR, Francais A, et al. Attributable mortality of ventilator-associated pneumonia: respective impact of main characteristics at ICU admission and VAP onset using conditional logistic regression and multi-state models. Intensive Care Med 2010;36(5):781-789.

18. Bekaert M, Timsit JF, Vansteelandt S, et al. Attributable mortality of ventilator associated pneumonia: a reappraisal using causal analysis. Am J Respir Crit Care Med 2011;184(10):11331139.

19. Melsen WG, Rovers MM, Koeman M, Bonten MJ. Estimating the attributable mortality of ventilator-associated pneumonia from randomized prevention studies. Crit Care Med 2011; 39(12):2736-2742.

20. Melsen WG, Rovers MM, Groenwold RH, et al. Attributable mortality of ventilator-associated pneumonia: a meta-analysis of individual patient data from randomised prevention studies. Lancet Infect Dis 2013;13(8):665-671.

21. Safdar N, Dezfulian C, Collard HR, Saint S. Clinical and economic consequences of ventilator-associated pneumonia: a systematic review. Crit Care Med 2005;33(10):2184-2193.

22. Kirtland SH, Corley DE, Winterbauer RH, et al. The diagnosis of ventilator-associated pneumonia: a comparison of histologic, microbiologic, and clinical criteria. Chest 1997;112(2):445-457.

23. Klompas M. Does this patient have ventilator-associated pneumonia? JAMA 2007;297(14):1583-1593.

24. Wunderink RG, Woldenberg LS, Zeiss J, Day CM, Ciemins J, Lacher DA. The radiologic diagnosis of autopsy-proven ventilator-associated pneumonia. Chest 1992;101(2):458-463.

25. Tejerina E, Esteban A, Fernandez-Segoviano P, et al. Accuracy of clinical definitions of ventilator-associated pneumonia: comparison with autopsy findings. $J$ Crit Care 2010;25(1):62-68.

26. Schurink CA, Van Nieuwenhoven CA, Jacobs JA, et al. Clinical pulmonary infection score for ventilator-associated pneumonia: accuracy and inter-observer variability. Intensive Care Med 2004;30(2):217-224.

27. Klompas $M$. Interobserver variability in ventilator-associated pneumonia surveillance. Am J Infect Control 2010;38(3):237239.

28. Klein Klouwenberg PM, Ong DS, Bos LD, et al. Interobserver agreement of Centers for Disease Control and Prevention criteria for classifying infections in critically ill patients. Crit Care Med 2013;41(10):2373-2378.

29. Stevens JP, Kachniarz B, Wright SB, et al. When policy gets it right: variability in U.S. hospitals' diagnosis of ventilatorassociated pneumonia. Crit Care Med 2014;42(3):497-503.

30. Sherman $\mathrm{ER}, \mathrm{Heydon} \mathrm{KH}$, St. John $\mathrm{KH}$, et al. Administrative data fail to accurately identify cases of healthcare-associated infection. Infect Control Hosp Epidemiol 2006;27(4):332-337.

31. Stevenson KB, Khan Y, Dickman J, et al. Administrative coding data, compared with CDC/NHSN criteria, are poor indicators of health care-associated infections. Am I Infect Control 2008; 36(3):155-164.

32. Drees M, Hausman S, Rogers A, Freeman L, Frosch K, Wroten $\mathrm{K}$. Underestimating the impact of ventilator-associated pneumonia by use of surveillance data. Infect Control Hosp Epidemiol 2010;31(6):650-652.

33. Klompas $M$. The paradox of ventilator-associated pneumonia prevention measures. Crit Care 2009;13(5):315.

34. Bonten MJ. Ventilator-associated pneumonia: preventing the inevitable. Clin Infect Dis 2011;52(1):115-121.

35. Klompas M, Platt R. Ventilator-associated pneumonia-the wrong quality measure for benchmarking. Ann Intern Med 2007;147(11):803-805.

36. van Saene HK, Silvestri L, de la Cal MA, Baines P. The emperor's new clothes: the fairy tale continues. J Crit Care 2009; 24(1):149-152.

37. Uckay I, Ahmed QA, Sax H, Pittet D. Ventilator-associated pneumonia as a quality indicator for patient safety? Clin Infect Dis 2008;46(4):557-563.

38. Blot S, Lisboa T, Angles R, Rello J. Prevention of VAP: is zero rate possible? Clin Chest Med 2011;32(3):591-599.

39. Magill SS, Klompas M, Balk R, et al. Developing a new, national approach to surveillance for ventilator-associated events. Crit Care Med 2013;41(11):2467-2475.

40. Klompas M, Kleinman K, Platt R. Development of an algorithm for surveillance of ventilator-associated pneumonia with electronic data and comparison of algorithm results with clinician diagnoses. Infect Control Hosp Epidemiol 2008;29(1):31-37.

41. Klompas M, Kleinman K, Khan Y, et al. Rapid and reproducible surveillance for ventilator-associated pneumonia. Clin Infect Dis 2012;54:370-377.

42. Dessap AM, Katsahian S, Roche-Campo F, et al. Ventilatorassociated pneumonia during weaning from mechanical ventilation: role of fluid management. Chest. doi:10.1378/chest.13 -2564. Electronically published March 20, 2014.

43. Centers for Disease Control and Prevention (CDC). VentilatorAssociated Event Protocol. Atlanta: CDC, 2014. http://www .cdc.gov/nhsn/acute-care-hospital/vae/index.html. Accessed March 25, 2014.

44. Klompas M. Ventilator-associated events surveillance: a patient safety opportunity. Curr Opin Crit Care 2013;19(5):424-431.

45. Lewis SC, Li L, Murphy MV, Klompas M. Risk factors for ventilator-associated events: a case-control multivariable analysis. Crit Care Med. doi:10.1097/CCM.0000000000000338. Electronically published April 18, 2014.

46. Strom T, Martinussen T, Toft P. A protocol of no sedation for critically ill patients receiving mechanical ventilation: a randomised trial. Lancet 2010;375(9713):475-480.

47. Ely EW, Baker AM, Dunagan DP, et al. Effect on the duration of mechanical ventilation of identifying patients capable of breathing spontaneously. N Engl J Med 1996;335(25):18641869.

48. Girard TD, Kress JP, Fuchs BD, et al. Efficacy and safety of a paired sedation and ventilator weaning protocol for mechanically ventilated patients in intensive care (Awakening and 
Breathing Controlled trial): a randomised controlled trial. Lancet 2008;371(9607):126-134.

49. Schweickert WD, Pohlman MC, Pohlman AS, et al. Early physical and occupational therapy in mechanically ventilated, critically ill patients: a randomised controlled trial. Lancet 2009; 373(9678):1874-1882.

50. Muscedere J, Rewa O, McKechnie K, Jiang X, Laporta D, Heyland DK. Subglottic secretion drainage for the prevention of ventilator-associated pneumonia: a systematic review and meta-analysis. Crit Care Med 2011;39(8):1985-1991.

51. Determann RM, Royakkers A, Wolthuis EK, et al. Ventilation with lower tidal volumes as compared with conventional tidal volumes for patients without acute lung injury: a preventive randomized controlled trial. Crit Care 2010;14(1):R1.

52. Futier E, Constantin J-M, Paugam-Burtz C, et al. A trial of intraoperative low-tidal-volume ventilation in abdominal surgery. N Engl J Med 2013;369(5):428-437.

53. Wiedemann HP, Wheeler AP, Bernard GR, et al. Comparison of two fluid-management strategies in acute lung injury. $N$ Engl J Med 2006;354(24):2564-2575.

54. Hebert PC, Wells G, Blajchman MA, et al; Transfusion Requirements in Critical Care Investigators, Canadian Critical Care Trials Group. A multicenter, randomized, controlled clinical trial of transfusion requirements in critical care. $N$ Engl $J$ Med 1999;340(6):409-417.

55. Klompas $M$. Prevention of ventilator-associated pneumonia. Expert Rev Anti Infect Ther 2010;8(7):791-800.

56. Bouadma L, Wolff M, Lucet JC. Ventilator-associated pneumonia and its prevention. Curr Opin Infect Dis 2012;25(4): 395-404.

57. Hess DR. Noninvasive positive-pressure ventilation and ventilator-associated pneumonia. Respir Care 2005;50(7):924-929.

58. Burns KE, Adhikari NK, Keenan SP, Meade MO. Noninvasive positive pressure ventilation as a weaning strategy for intubated adults with respiratory failure. Cochrane Database Syst Rev 2010(8):CD004127.

59. Carron M, Freo U, BaHammam AS, et al. Complications of non-invasive ventilation techniques: a comprehensive qualitative review of randomized trials. Br I Anaesth 2013;110(6): 896-914.

60. Aboussouan LS, Ricaurte B. Noninvasive positive pressure ventilation: increasing use in acute care. Cleve Clin J Med 2010; 77(5):307-316.

61. Barr J, Fraser GL, Puntillo K, et al. Clinical practice guidelines for the management of pain, agitation, and delirium in adult patients in the intensive care unit. Crit Care Med 2013;41(1): 263-306.

62. Kress JP, Pohlman AS, O'Connor MF, Hall JB. Daily interruption of sedative infusions in critically ill patients undergoing mechanical ventilation. $N$ Engl J Med 2000;342(20):1471-1477.

63. Schweickert WD, Gehlbach BK, Pohlman AS, Hall JB, Kress JP. Daily interruption of sedative infusions and complications of critical illness in mechanically ventilated patients. Crit Care Med 2004;32(6):1272-1276.

64. Mehta S, Burry L, Cook D, et al. Daily sedation interruption in mechanically ventilated critically ill patients cared for with a sedation protocol. JAMA 2012:308(19):1985-1992.

65. Kress JP, Hall JB. The changing landscape of ICU sedation. JAMA 2012;308(19):2030-2031.

66. Kollef MH, Shapiro SD, Silver $\mathrm{P}$, et al. A randomized, controlled trial of protocol-directed versus physician-directed weaning from mechanical ventilation. Crit Care Med 1997;25(4):567574.

67. Marelich GP, Murin S, Battistella F, Inciardi J, Vierra T, Roby $M$. Protocol weaning of mechanical ventilation in medical and surgical patients by respiratory care practitioners and nurses: effect on weaning time and incidence of ventilator-associated pneumonia. Chest 2000;118(2):459-467.

68. Lellouche F, Mancebo J, Jolliet P, et al. A multicenter randomized trial of computer-driven protocolized weaning from mechanical ventilation. Am J Respir Crit Care Med 2006;174(8): 894-900.

69. Esteban A, Frutos F, Tobin MJ, et al; Spanish Lung Failure Collaborative Group. A comparison of four methods of weaning patients from mechanical ventilation. $N$ Engl J Med 1995; 332(6):345-350.

70. Hopkins RO, Spuhler VJ, Thomsen GE. Transforming ICU culture to facilitate early mobility. Crit Care Clin 2007;23(1): 81-96.

71. Morris PE, Goad A, Thompson C, et al. Early intensive care unit mobility therapy in the treatment of acute respiratory failure. Crit Care Med 2008;36(8):2238-2243.

72. Bailey $P$, Thomsen GE, Spuhler VJ, et al. Early activity is feasible and safe in respiratory failure patients. Crit Care Med 2007; 35(1):139-145.

73. Morris PE, Griffin L, Berry M, et al. Receiving early mobility during an intensive care unit admission is a predictor of improved outcomes in acute respiratory failure. Am J Med Sci 2011;341(5):373-377.

74. Burtin C, Clerckx B, Robbeets C, et al. Early exercise in critically ill patients enhances short-term functional recovery. Crit Care Med 2009;37(9):2499-2505.

75. Needham DM, Korupolu R, Zanni JM, et al. Early physical medicine and rehabilitation for patients with acute respiratory failure: a quality improvement project. Arch Phys Med Rehabil 2010;91(4):536-542.

76. Titsworth WL, Hester J, Correia T, et al. The effect of increased mobility on morbidity in the neurointensive care unit. $J \mathrm{Neu}$ rosurg 2012;116(6):1379-1388.

77. Balas MC, Vasilevskis EE, Olsen KM, et al. Effectiveness and safety of the awakening and breathing coordination, delirium monitoring/management, and early exercise/mobility bundle. Crit Care Med 2014;42(5):1024-1036.

78. Lord RK, Mayhew CR, Korupolu R, et al. ICU early physical rehabilitation programs: financial modeling of cost savings. Crit Care Med 2013;41(3):717-724.

79. Bouza E, Perez MJ, Munoz P, Rincon C, Barrio JM, Hortal J. Continuous aspiration of subglottic secretions in the prevention of ventilator-associated pneumonia in the postoperative period of major heart surgery. Chest 2008;134(5):938-946.

80. Lacherade JC, De Jonghe B, Guezennec $P$, et al. Intermittent subglottic secretion drainage and ventilator-associated pneumonia: a multicenter trial. Am J Respir Crit Care Med 2010; 182(7):910-917.

81. Shorr AF, O'Malley PG. Continuous subglottic suctioning for the prevention of ventilator-associated pneumonia: potential economic implications. Chest 2001;119(1):228-235.

82. Hallais C, Merle V, Guitard PG, et al. Is continuous subglottic suctioning cost-effective for the prevention of ventilator- 
associated pneumonia? Infect Control Hosp Epidemiol 2011; 32(2):131-135.

83. Frost SA, Azeem A, Alexandrou E, et al. Subglottic secretion drainage for preventing ventilator associated pneumonia: a meta-analysis. Aust Crit Care 2013;26(4):180-188.

84. Drakulovic MB, Torres A, Bauer TT, Nicolas JM, Nogue S, Ferrer M. Supine body position as a risk factor for nosocomial pneumonia in mechanically ventilated patients: a randomised trial. Lancet 1999;354(9193):1851-1858.

85. van Nieuwenhoven CA, Vandenbroucke-Grauls C, van Tiel FH, et al. Feasibility and effects of the semirecumbent position to prevent ventilator-associated pneumonia: a randomized study. Crit Care Med 2006;34(2):396-402.

86. Keeley L. Reducing the risk of ventilator-acquired pneumonia through head of bed elevation. Nurs Crit Care 2007;12(6):287294.

87. Alexiou VG, Ierodiakonou V, Dimopoulos G, Falagas ME. Impact of patient position on the incidence of ventilator-associated pneumonia: a meta-analysis of randomized controlled trials. J Crit Care 2009;24(4):515-522.

88. Dreyfuss D, Djedaini K, Weber P, et al. Prospective study of nosocomial pneumonia and of patient and circuit colonization during mechanical ventilation with circuit changes every 48 hours versus no change. Am Rev Respir Dis 1991;143(4 pt 1): $738-743$.

89. Kollef MH, Shapiro SD, Fraser VJ, et al. Mechanical ventilation with or without 7-day circuit changes: a randomized controlled trial. Ann Intern Med 1995;123(3):168-174.

90. Long MN, Wickstrom G, Grimes A, Benton CF, Belcher B, Stamm AM. Prospective, randomized study of ventilatorassociated pneumonia in patients with one versus three ventilator circuit changes per week. Infect Control Hosp Epidemiol 1996;17(1):14-19.

91. Lorente L, Lecuona M, Galvan R, Ramos MJ, Mora ML, Sierra A. Periodically changing ventilator circuits is not necessary to prevent ventilator-associated pneumonia when a heat and moisture exchanger is used. Infect Control Hosp Epidemiol 2004; 25(12):1077-1082.

92. Rutala WA, Weber DJ; Healthcare Infection Control Practices Advisory Committee. Guideline for Disinfection and Sterilization in Healthcare Facilities, 2008. http://www.cdc.gov/hicpac /Disinfection_Sterilization/acknowledg.html. Accessed April 1, 2014.

93. Krueger WA, Lenhart FP, Neeser G, et al. Influence of combined intravenous and topical antibiotic prophylaxis on the incidence of infections, organ dysfunctions, and mortality in critically ill surgical patients: a prospective, stratified, randomized, doubleblind, placebo-controlled clinical trial. Am J Respir Crit Care Med 2002;166(8):1029-1037.

94. de Jonge E, Schultz MJ, Spanjaard L, et al. Effects of selective decontamination of digestive tract on mortality and acquisition of resistant bacteria in intensive care: a randomised controlled trial. Lancet 2003;362(9389):1011-1016.

95. de Smet AM, Kluytmans JA, Cooper BS, et al. Decontamination of the digestive tract and oropharynx in ICU patients. $N$ Engl $J$ Med 2009;360(1):20-31.

96. Liberati A, D'Amico R, Pifferi S, Torri V, Brazzi L, Parmelli E. Antibiotic prophylaxis to reduce respiratory tract infections and mortality in adults receiving intensive care. Cochrane Database Syst Rev 2009(4):CD000022.
97. de Smet AM, Kluytmans IA, Blok HE, et al. Selective digestive tract decontamination and selective oropharyngeal decontamination and antibiotic resistance in patients in intensive-care units: an open-label, clustered group-randomised, crossover study. Lancet Infect Dis 2011;11(5):372-380.

98. Chan EY, Ruest A, Meade MO, Cook DJ. Oral decontamination for prevention of pneumonia in mechanically ventilated adults: systematic review and meta-analysis. BMJ 2007;334(7599):889.

99. Daneman N, Sarwar S, Fowler RA, Cuthbertson BH. Effect of selective decontamination on antimicrobial resistance in intensive care units: a systematic review and meta-analysis. Lancet Infect Dis 2013;13(4):328-341.

100. van der Meer JW, Vandenbroucke-Grauls CM. Resistance to selective decontamination: the jury is still out. Lancet Infect Dis 2013;13(4):282-283.

101. Chlebicki MP, Safdar N. Topical chlorhexidine for prevention of ventilator-associated pneumonia: a meta-analysis. Crit Care Med 2007;35(2):595-602.

102. Pileggi C, Bianco A, Flotta D, Nobile CG, Pavia M. Prevention of ventilator-associated pneumonia, mortality and all intensive care unit acquired infections by topically applied antimicrobial or antiseptic agents: a meta-analysis of randomized controlled trials in intensive care units. Crit Care 2011;15(3):R155.

103. Labeau SO, Van de Vyver K, Brusselaers N, Vogelaers D, Blot SI. Prevention of ventilator-associated pneumonia with oral antiseptics: a systematic review and meta-analysis. Lancet Infect Dis 2011;11(11):845-854.

104. Tantipong H, Morkchareonpong C, Jaiyindee S, Thamlikitkul V. Randomized controlled trial and meta-analysis of oral decontamination with $2 \%$ chlorhexidine solution for the prevention of ventilator-associated pneumonia. Infect Control Hosp Epidemiol 2008;29(2):131-136.

105. Li J, Xie D, Li A, Yue J. Oral topical decontamination for preventing ventilator-associated pneumonia: a systematic review and meta-analysis of randomized controlled trials. J Hosp Infect 2013;84(4):283-293.

106. Shi $\mathrm{Z}$, Xie $\mathrm{H}$, Wang $\mathrm{P}$, et al. Oral hygiene care for critically ill patients to prevent ventilator-associated pneumonia. Cochrane Database Syst Rev 2013;8:CD008367.

107. Silvestri L, Weir I, Gregori D, et al. Effectiveness of oral chlorhexidine on nosocomial pneumonia, causative microorganisms and mortality in critically ill patients: a systematic review and meta-analysis. Minerva Anestesiol. Electronically published November 21, 2013.

108. Klompas M, Speck K, Howell MD, Greene LR, Berenholtz SM. Reappraisal of routine oral care with chlorhexidine gluconate for patients receiving mechanical ventilation: systematic review and meta-analysis. JAMA Intern Med 2014;174(5):751-761.

109. DeRiso AJ 2nd, Ladowski JS, Dillon TA, Justice JW, Peterson AC. Chlorhexidine gluconate $0.12 \%$ oral rinse reduces the incidence of total nosocomial respiratory infection and nonprophylactic systemic antibiotic use in patients undergoing heart surgery. Chest 1996;109(6):1556-1561.

110. Segers P, Speekenbrink RG, Ubbink DT, van Ogtrop ML, de Mol BA. Prevention of nosocomial infection in cardiac surgery by decontamination of the nasopharynx and oropharynx with chlorhexidine gluconate: a randomized controlled trial. JAMA 2006;296(20):2460-2466.

111. Siempos II, Ntaidou TK, Falagas ME. Impact of the administration of probiotics on the incidence of ventilator-associated 
pneumonia: a meta-analysis of randomized controlled trials. Crit Care Med 2010;38(3):954-962.

112. Liu KX, Zhu YG, Zhang J, et al. Probiotics' effects on the incidence of nosocomial pneumonia in critically ill patients: a systematic review and meta-analysis. Crit Care 2012;16(3): R109.

113. Petrof EO, Dhaliwal R, Manzanares W, Johnstone J, Cook D, Heyland DK. Probiotics in the critically ill: a systematic review of the randomized trial evidence. Crit Care Med 2012;40(12): 3290-3302.

114. Barraud D, Bollaert PE, Gibot S. Impact of the administration of probiotics on mortality in critically ill adult patients: a metaanalysis of randomized controlled trials. Chest 2013;143(3): 646-655.

115. Lherm T, Monet C, Nougiere B, et al. Seven cases of fungemia with Saccharomyces boulardii in critically ill patients. Intensive Care Med 2002;28(6):797-801.

116. Munoz P, Bouza E, Cuenca-Estrella M, et al. Saccharomyces cerevisiae fungemia: an emerging infectious disease. Clin Infect Dis 2005;40(11):1625-1634.

117. Salminen MK, Rautelin H, Tynkkynen S, et al. Lactobacillus bacteremia, clinical significance, and patient outcome, with special focus on probiotic L. rhamnosus GG. Clin Infect Dis 2004;38(1):62-69.

118. Cassone M, Serra P, Mondello F, et al. Outbreak of Saccharomyces cerevisiae subtype boulardii fungemia in patients neighboring those treated with a probiotic preparation of the organism. $J$ Clin Microbiol 2003;41(11):5340-5343.

119. Graf C, Gavazzi G. Saccharomyces cerevisiae fungemia in an immunocompromised patient not treated with Saccharomyces boulardii preparation. I Infect 2007;54(3):310-311.

120. Lorente L, Lecuona M, Jimenez A, Mora ML, Sierra A. Influence of an endotracheal tube with polyurethane cuff and subglottic secretion drainage on pneumonia. Am J Respir Crit Care Med 2007;176(11):1079-1083.

121. Poelaert J, Depuydt P, De Wolf A, Van de Velde S, Herck I, Blot S. Polyurethane cuffed endotracheal tubes to prevent early postoperative pneumonia after cardiac surgery: a pilot study. $J$ Thorac Cardiovasc Surg 2008;135(4):771-776.

122. Valencia M, Ferrer M, Farre R, et al. Automatic control of tracheal tube cuff pressure in ventilated patients in semirecumbent position: a randomized trial. Crit Care Med 2007; 35(6):1543-1549.

123. Nseir S, Zerimech F, Fournier C, et al. Continuous control of tracheal cuff pressure and microaspiration of gastric contents in critically ill patients. Am J Respir Crit Care Med 2011;184(9): 1041-1047.

124. Caruso P, Denari S, Ruiz SA, Demarzo SE, Deheinzelin D. Saline instillation before tracheal suctioning decreases the incidence of ventilator-associated pneumonia. Crit Care Med 2009;37(1):32-38.

125. Yao LY, Chang CK, Maa SH, Wang C, Chen CC. Brushing teeth with purified water to reduce ventilator-associated pneumonia. J Nurs Res 2011;19(4):289-297.

126. Alhazzani W, Smith O, Muscedere J, Medd J, Cook D. Toothbrushing for critically ill mechanically ventilated patients: a systematic review and meta-analysis of randomized trials evaluating ventilator-associated pneumonia. Crit Care Med 2013; 41(2):646-655.

127. Kollef $\mathrm{MH}$, Afessa B, Anzueto A, et al. Silver-coated endotra- cheal tubes and incidence of ventilator-associated pneumonia: the NASCENT randomized trial. JAMA 2008;300(7):805-813.

128. Delaney A, Gray H, Laupland KB, Zuege DJ. Kinetic bed therapy to prevent nosocomial pneumonia in mechanically ventilated patients: a systematic review and meta-analysis. Crit Care 2006;10(3):R70.

129. Sud S, Sud M, Friedrich JO, Adhikari NK. Effect of mechanical ventilation in the prone position on clinical outcomes in patients with acute hypoxemic respiratory failure: a systematic review and meta-analysis. Can Med Assoc J 2008;178(9):11531161.

130. Alsaghir AH, Martin CM. Effect of prone positioning in patients with acute respiratory distress syndrome: a meta-analysis. Crit Care Med 2008;36(2):603-609.

131. Abroug F, Ouanes-Besbes L, Elatrous S, Brochard L. The effect of prone positioning in acute respiratory distress syndrome or acute lung injury: a meta-analysis. Areas of uncertainty and recommendations for research. Intensive Care Med 2008;34(6): 1002-1011.

132. Kopterides P, Siempos, II, Armaganidis A. Prone positioning in hypoxemic respiratory failure: meta-analysis of randomized controlled trials. J Crit Care 2009;24(1):89-100.

133. Abroug F, Ouanes-Besbes L, Dachraoui F, Ouanes I, Brochard L. An updated study-level meta-analysis of randomised controlled trials on proning in ARDS and acute lung injury. Crit Care 2011;15(1):R6.

134. Guerin C, Reignier J, Richard JC, et al. Prone positioning in severe acute respiratory distress syndrome. $\mathrm{N}$ Engl J Med 2013; 368(23):2159-2168.

135. Marik PE, Vasu T, Hirani A, Pachinburavan M. Stress ulcer prophylaxis in the new millennium: a systematic review and meta-analysis. Crit Care Med 2010;38(11):2222-2228.

136. Alhazzani W, Alenezi F, Jaeschke RZ, Moayyedi P, Cook DJ. Proton pump inhibitors versus histamine 2 receptor antagonists for stress ulcer prophylaxis in critically ill patients: a systematic review and meta-analysis. Crit Care Med 2013;41(3): 693-705.

137. Wang $\mathrm{F}, \mathrm{Wu} \mathrm{Y}, \mathrm{Bo} \mathrm{L}$, et al. The timing of tracheotomy in critically ill patients undergoing mechanical ventilation: a systematic review and meta-analysis of randomized controlled trials. Chest 2011;140(6):1456-1465.

138. Reignier J, Mercier E, Le Gouge A, et al. Effect of not monitoring residual gastric volume on risk of ventilator-associated pneumonia in adults receiving mechanical ventilation and early enteral feeding: a randomized controlled trial. JAMA 2013; 309(3):249-256.

139. Casaer MP, Mesotten D, Hermans G, et al. Early versus late parenteral nutrition in critically ill adults. N Engl J Med 2011; 365(6):506-517.

140. Vonberg RP, Eckmanns T, Welte T, Gastmeier P. Impact of the suctioning system (open vs. closed) on the incidence of ventilation-associated pneumonia: meta-analysis of randomized controlled trials. Intensive Care Med 2006;32(9):1329-1335.

141. Jongerden IP, Rovers MM, Grypdonck MH, Bonten MJ. Open and closed endotracheal suction systems in mechanically ventilated intensive care patients: a meta-analysis. Crit Care Med 2007;35(1):260-270.

142. Siempos II, Vardakas KZ, Falagas ME. Closed tracheal suction systems for prevention of ventilator-associated pneumonia. $\mathrm{Br}$ J Anaesth 2008;100(3):299-306. 
143. Jongerden IP, Buiting AG, Leverstein-van Hall MA, et al. Effect of open and closed endotracheal suctioning on cross-transmission with gram-negative bacteria: a prospective crossover study. Crit Care Med 2011;39(6):1313-1321.

144. Lorente L, Lecuona M, Jimenez A, Mora ML, Sierra A. Tracheal suction by closed system without daily change versus open system. Intensive Care Med 2006;32(4):538-544.

145. Maggiore SM. Endotracheal suctioning, ventilator-associated pneumonia, and costs: open or closed issue? Intensive Care Med 2006;32(4):485-487.

146. Dudeck MA, Horan T, Peterson $\mathrm{KD}$, et al. National Healthcare Safety Network (NHSN) Report, Data Summary for 2011, DeviceAssociated Module. Atlanta: Centers for Disease Control and Prevention, 2013. http://www.cdc.gov/nhsn/PDFs/dataStat/NHSN -Report-2011-Data-Summary.pdf. Accessed April 1, 2014.

147. Bhandari V, Finer NN, Ehrenkranz RA, et al. Synchronized nasal intermittent positive-pressure ventilation and neonatal outcomes. Pediatrics 2009;124(2):517-526.

148. Finer NN, Carlo WA, Walsh MC, et al. Early CPAP versus surfactant in extremely preterm infants. $N$ Engl J Med 2010; 362(21):1970-1979.

149. Bhandari V. Nasal intermittent positive pressure ventilation in the newborn: review of literature and evidence-based guidelines. J Perinatol 2010;30(8):505-512.

150. Hamid MH, Malik MA, Masood J, Zia A, Ahmad TM. Ventilator-associated pneumonia in children. J Coll Physicians Surg Pak 2012;22(3):155-158.

151. $\mathrm{Ng}$ E, Taddio A, Ohlsson A. Intravenous midazolam infusion for sedation of infants in the neonatal intensive care unit. Cochrane Database Syst Rev 2012;6:CD002052.

152. Veldman A, Trautschold T, Weiss K, Fischer D, Bauer K. Characteristics and outcome of unplanned extubation in ventilated preterm and term newborns on a neonatal intensive care unit. Paediatr Anaesth 2006;16(9):968-973.

153. Samransamruajkit R, Jirapaiboonsuk S, Siritantiwat $S$, et al. Effect of frequency of ventilator circuit changes ( 3 vs 7 days) on the rate of ventilator-associated pneumonia in PICU. J Crit Care 2010;25(1):56-61.

154. Hsieh TC, Hsia SH, Wu CT, Lin TY, Chang CC, Wong KS. Frequency of ventilator-associated pneumonia with 3-day versus 7-day ventilator circuit changes. Pediatr Neonatol 2010; 51(1):37-43.

155. Aly H, Badawy M, El-Kholy A, Nabil R, Mohamed A. Randomized, controlled trial on tracheal colonization of ventilated infants: can gravity prevent ventilator-associated pneumonia? Pediatrics 2008;122(4):770-774.

156. Taylor JE, Hawley G, Flenady V, Woodgate PG. Tracheal suctioning without disconnection in intubated ventilated neonates. Cochrane Database Syst Rev 2011(12):CD003065.

157. van Veenendaal $M B$, Miedema $M$, de Jongh $F H$, van der Lee JH, Frerichs I, van Kaam AH. Effect of closed endotracheal suction in high-frequency ventilated premature infants measured with electrical impedance tomography. Intensive Care Med 2009;35(12):2130-2134.

158. Terrin G, Passariello A, De Curtis $M$, et al. Ranitidine is associated with infections, necrotizing enterocolitis, and fatal outcome in newborns. Pediatrics 2012;129(1):e40-e45.

159. Guillet R, Stoll BJ, Cotten CM, et al. Association of $\mathrm{H} 2$-blocker therapy and higher incidence of necrotizing enterocolitis in very low birth weight infants. Pediatrics 2006;117(2):e137el 42 .

160. Kuppala VS, Meinzen-Derr J, Morrow AL, Schibler KR. Prolonged initial empirical antibiotic treatment is associated with adverse outcomes in premature infants. J Pediatr 2011;159(5): $720-725$.

161. Alexander VN, Northrup V, Bizzarro MJ. Antibiotic exposure in the newborn intensive care unit and the risk of necrotizing enterocolitis. J Pediatr 2011;159(3):392-397.

162. Shah P, Nathan E, Doherty D, Patole S. Prolonged exposure to antibiotics and its associations in extremely preterm neonates-the western Australian experience. J Matern Fetal Neonatal Med 2013;26(17):1710-1714.

163. Weintraub AS, Ferrara L, Deluca L, et al. Antenatal antibiotic exposure in preterm infants with necrotizing enterocolitis. $J$ Perinatol 2012;32(9):705-709.

164. Davis PG, Henderson-Smart DJ. Extubation from low-rate intermittent positive airways pressure versus extubation after a trial of endotracheal continuous positive airways pressure in intubated preterm infants. Cochrane Database Syst Rev 2001(4): CD001078.

165. Kaczmarek J, Kamlin CO, Morley CJ, Davis PG, Sant'anna GM. Variability of respiratory parameters and extubation readiness in ventilated neonates. Arch Dis Child Fetal Neonatal Ed 2013; 98(1):F70-F73.

166. Kamlin CO, Davis PG, Argus B, Mills B, Morley CJ. A trial of spontaneous breathing to determine the readiness for extubation in very low birth weight infants: a prospective evaluation. Arch Dis Child Fetal Neonatal Ed 2008;93(4):F305-F306.

167. Rojas MA, Lozano JM, Rojas MX, et al. Prophylactic probiotics to prevent death and nosocomial infection in preterm infants. Pediatrics 2012;130(5):e1113-e1120.

168. Manzoni P, Mostert M, Leonessa ML, et al. Oral supplementation with Lactobacillus casei subspecies rhamnosus prevents enteric colonization by Candida species in preterm neonates: a randomized study. Clin Infect Dis 2006;42(12):1735-1742.

169. De Groote MA, Frank DN, Dowell E, Glode MP, Pace NR. Lactobacillus rhamnosus GG bacteremia associated with probiotic use in a child with short gut syndrome. Pediatr Infect Dis J 2005;24(3):278-280.

170. Kunz AN, Noel JM, Fairchok MP. Two cases of Lactobacillus bacteremia during probiotic treatment of short gut syndrome. J Pediatr Gastroenterol Nutr 2004;38(4):457-458.

171. Land MH, Rouster-Stevens K, Woods CR, Cannon ML, Cnota J, Shetty AK. Lactobacillus sepsis associated with probiotic therapy. Pediatrics 2005;115(1):178-181.

172. Foglia E, Meier MD, Elward A. Ventilator-associated pneumonia in neonatal and pediatric intensive care unit patients. Clin Microbiol Rev 2007;20(3):409-425.

173. Bigham MT, Amato $R$, Bondurrant $\mathbf{P}$, et al. Ventilator-associated pneumonia in the pediatric intensive care unit: characterizing the problem and implementing a sustainable solution. J Pediatr 2009;154(4):582e2-587e2.

174. Taira BR, Fenton KE, Lee TK, et al. Ventilator-associated pneumonia in pediatric trauma patients. Pediatr Crit Care Med 2009; 10(4):491-494.

175. Gautam A, Ganu SS, Tegg OJ, Andresen DN, Wilkins BH, Schell DN. Ventilator-associated pneumonia in a tertiary paediatric intensive care unit: a 1-year prospective observational study. Crit Care Resusc 2012;14(4):283-289. 
176. Awasthi S, Tahazzul M, Ambast A, Govil YC, Jain A. Longer duration of mechanical ventilation was found to be associated with ventilator-associated pneumonia in children aged 1 month to 12 years in India. I Clin Epidemiol 2013;66(1):62-66.

177. Liljemark WF, Bloomquist C. Human oral microbial ecology and dental caries and periodontal diseases. Crit Rev Oral Biol Med 1996;7(2):180-198.

178. Kononen E. Development of oral bacterial flora in young children. Ann Med 2000;32(2):107-112.

179. Javouhey E, Barats A, Richard N, Stamm D, Floret D. Noninvasive ventilation as primary ventilatory support for infants with severe bronchiolitis. Intensive Care Med 2008;34(9):16081614.

180. Yanez LJ, Yunge M, Emilfork M, et al. A prospective, randomized, controlled trial of noninvasive ventilation in pediatric acute respiratory failure. Pediatr Crit Care Med 2008;9(5):484 489.

181. Ferguson LP, Walsh BK, Munhall D, Arnold JH. A spontaneous breathing trial with pressure support overestimates readiness for extubation in children. Pediatr Crit Care Med 2011;12(6): e330-e335.

182. Randolph AG, Wypij D, Venkataraman ST, et al. Effect of mechanical ventilator weaning protocols on respiratory outcomes in infants and children: a randomized controlled trial. JAMA 2002;288(20):2561-2568.

183. Foronda FK, Troster EJ, Farias JA, et al. The impact of daily evaluation and spontaneous breathing test on the duration of pediatric mechanical ventilation: a randomized controlled trial. Crit Care Med 2011;39(11):2526-2533.

184. Newth CJ, Venkataraman S, Willson DF, et al. Weaning and extubation readiness in pediatric patients. Pediatr Crit Care Med 2009;10(1):1-11.

185. Lucas da Silva PS, de Carvalho WB. Unplanned extubation in pediatric critically ill patients: a systematic review and best practice recommendations. Pediatr Crit Care Med 2010;11(2): 287-294.

186. Curley MA, Schwalenstocker E, Deshpande JK, et al. Tailoring the Institute for Health Care Improvement 100,000 Lives Campaign to pediatric settings: the example of ventilator-associated pneumonia. Pediatr Clin North Am 2006;53(6):1231-1251.

187. American Dental Association. Your child's growing smile. J Am Dent Assoc 2012;143(1):88.

188. Tsai HH, Lin FC, Chang SC. Intermittent suction of oral secretions before each positional change may reduce ventilatorassociated pneumonia: a pilot study. Am J Med Sci 2008;336(5): 397-401.

189. Gopalareddy V, He Z, Soundar S, et al. Assessment of the prevalence of microaspiration by gastric pepsin in the airway of ventilated children. Acta Paediatr 2008;97(1):55-60.

190. Weiss M, Dullenkopf A, Fischer JE, Keller C, Gerber AC. Prospective randomized controlled multi-centre trial of cuffed or uncuffed endotracheal tubes in small children. $\mathrm{Br} J$ Anaesth 2009;103(6):867-873.

191. Kleinman ME, de Caen AR, Chameides L, et al. Part 10: pediatric basic and advanced life support: 2010 International Consensus on Cardiopulmonary Resuscitation and Emergency Cardiovascular Care Science with Treatment Recommendations. Circulation 2010;122(16 suppl 2):S466-S515.

192. Gupta K, Gupta VK, Jayashree M, Singhi S. Randomized controlled trial of interrupted versus continuous sedative infusions in ventilated children. Pediatr Crit Care Med 2012;13(2):131135.

193. Sebastian MR, Lodha R, Kapil A, Kabra SK. Oral mucosal decontamination with chlorhexidine for the prevention of ventilator-associated pneumonia in children-a randomized, controlled trial. Pediatr Crit Care Med 2012;13(5):e305-e310.

194. Wan AK, Seow WK, Purdie DM, Bird PS, Walsh LJ, Tudehope DI. The effects of chlorhexidine gel on Streptococcus mutans infection in 10-month-old infants: a longitudinal, placebo-controlled, double-blind trial. Pediatr Dent 2003;25(3):215-222.

195. Jacomo AD, Carmona F, Matsuno AK, Manso PH, Carlotti AP. Effect of oral hygiene with $0.12 \%$ chlorhexidine gluconate on the incidence of nosocomial pneumonia in children undergoing cardiac surgery. Infect Control Hosp Epidemiol 201 1;32(6): 591-596.

196. Kusahara DM, Friedlander LT, Peterlini MA, Pedreira ML. Oral care and oropharyngeal and tracheal colonization by gramnegative pathogens in children. Nurs Crit Care 2012;17(3):115122.

197. Kusahara DM, Peterlini MA, Pedreira ML. Oral care with $0.12 \%$ chlorhexidine for the prevention of ventilator-associated pneumonia in critically ill children: randomised, controlled and double blind trial. Int J Nurs Stud 2012;49(11):1354-1363.

198. Pedreira ML, Kusahara DM, de Carvalho WB, Nunez SC, Peterlini MA. Oral care interventions and oropharyngeal colonization in children receiving mechanical ventilation. $A m J$ Crit Care 2009;18(4):319-328.

199. Yildizdas D, Yapicioglu H, Yilmaz HL. Occurrence of ventilator-associated pneumonia in mechanically ventilated pediatric intensive care patients during stress ulcer prophylaxis with sucralfate, ranitidine, and omeprazole. J Crit Care 2002;17(4): 240-245.

200. Lopriore E, Markhorst DG, Gemke RJ. Ventilator-associated pneumonia and upper airway colonisation with gram negative bacilli: the role of stress ulcer prophylaxis in children. Intensive Care Med 2002;28(6):763-767.

201. Morrow BM, Mowzer R, Pitcher R, Argent AC. Investigation into the effect of closed-system suctioning on the frequency of pediatric ventilator-associated pneumonia in a developing country. Pediatr Crit Care Med 2012;13(1):e25-e32.

202. Hatler CW, Mast D, Corderella J, et al. Using evidence and process improvement strategies to enhance healthcare outcomes for the critically ill: a pilot project. Am J Crit Care 2006; 15(6):549-555.

203. Pronovost PJ, Berenholtz SM, Needham DM. Translating evidence into practice: a model for large scale knowledge translation. BMJ 2008;337:a1714.

204. Krimsky WS, Mroz IB, McIlwaine JK, et al. A model for increasing patient safety in the intensive care unit: increasing the implementation rates of proven safety measures. Qual Saf Health Care 2009;18(1):74-80.

205. Hawe CS, Ellis KS, Cairns CI, Longmate A. Reduction of ventilator-associated pneumonia: active versus passive guideline implementation. Intensive Care Med 2009;35(7):1180-1186.

206. Rello J, Lode H, Cornaglia G, Masterton R. A European care bundle for prevention of ventilator-associated pneumonia. Intensive Care Med 2010;36(5):773-780.

207. Berenholtz SM, Pham JC, Thompson DA, et al. Collaborative cohort study of an intervention to reduce ventilator-associated 
pneumonia in the intensive care unit. Infect Control Hosp Epidemiol 2011;32(4):305-314.

208. Klompas M. Ventilator-associated pneumonia: is zero possible? Clin Infect Dis 2010;51(10):1123-1126.

209. Crunden E, Boyce C, Woodman H, Bray B. An evaluation of the impact of the ventilator care bundle. Nurs Crit Care 2005; 10(5):242-246.

210. Burger CD, Resar RK. "Ventilator bundle" approach to prevention of ventilator-associated pneumonia. Mayo Clin Proc 2006;81(6):849-850.

211. Apisarnthanarak A, Pinitchai U, Thongphubeth $K$, et al. Effectiveness of an educational program to reduce ventilatorassociated pneumonia in a tertiary care center in Thailand: a 4-year study. Clin Infect Dis 2007;45(6):704-711.

212. Youngquist $P$, Carroll $M$, Farber $M$, et al. Implementing a ventilator bundle in a community hospital. It Comm J Qual Patient Saf 2007;33(4):219-225.

213. Bloos F, Muller S, Harz A, et al. Effects of staff training on the care of mechanically ventilated patients: a prospective cohort study. Br J Anaesth 2009;103(2):232-237.

214. Sinuff T, Muscedere J, Cook DJ, et al. Implementation of clinical practice guidelines for ventilator-associated pneumonia: a multicenter prospective study. Crit Care Med 2013;41(1):15-23.

215. Resar R, Pronovost P, Haraden C, Simmonds T, Rainey T, Nolan T. Using a bundle approach to improve ventilator care processes and reduce ventilator-associated pneumonia. It Comm J Qual Patient Saf 2005;31(5):243-248.

216. Ellingson K, Haas JP, Aiello AE, et al. Strategies to prevent healthcare-associated infections through hand hygiene. Infect Control Hosp Epidemiol 35(8):937-960 (in this issue).

217. Boles JM, Bion J, Connors A, et al. Weaning from mechanical ventilation. Eur Respir J 2007;29(5):1033-1056.

218. Aragon D, Sole ML. Implementing best practice strategies to prevent infection in the ICU. Crit Care Nurs Clin North Am 2006;18(4):441-452.

219. Burns SM, Earven S, Fisher C, et al. Implementation of an institutional program to improve clinical and financial outcomes of mechanically ventilated patients: one-year outcomes and lessons learned. Crit Care Med 2003;31(12):2752-2763.

220. Brierley J, Highe L, Hines S, Dixon G. Reducing VAP by instituting a care bundle using improvement methodology in a UK paediatric intensive care unit. Eur J Pediatr 2012;171(2): 323-330.

221. Weireter LJ Jr, Collins JN, Britt RC, Reed SF, Novosel TJ, Britt LD. Impact of a monitored program of care on incidence of ventilator-associated pneumonia: results of a longterm performance-improvement project. J Am Coll Surg 2009;208(5):700704.

222. Johnson V, Mangram A, Mitchell C, Lorenzo M, Howard D, Dunn $E$. Is there a benefit to multidisciplinary rounds in an open trauma intensive care unit regarding ventilator-associated pneumonia? Am Surg 2009;75(12):1171-1174.

223. Heimes J, Braxton C, Nazir N, et al. Implementation and enforcement of ventilator-associated pneumonia prevention strategies in trauma patients. Surg Infect (Larchmt) 2011;12(2): 99-103.

224. Craven DE. Preventing ventilator-associated pneumonia in adults: sowing seeds of change. Chest 2006;130(1):251-260.

225. Mangino JE, Peyrani P, Ford KD, et al. Development and im- plementation of a performance improvement project in adult intensive care units: overview of the Improving Medicine Through Pathway Assessment of Critical Therapy in HospitalAcquired Pneumonia (IMPACT-HAP) study. Crit Care 2011; 15(1):R38.

226. Scales DC, Dainty K, Hales B, et al. A multifaceted intervention for quality improvement in a network of intensive care units: a cluster randomized trial. JAMA 2011;305(4):363-372.

227. Rello J, Afonso E, Lisboa T, et al. A care bundle approach for prevention of ventilator-associated pneumonia. Clin Microbiol Infect 2013;19(4):363-369.

228. Grimshaw J, Eccles M, Thomas R, et al. Toward evidence-based quality improvement: evidence (and its limitations) of the effectiveness of guideline dissemination and implementation strategies 1966-1998. J Gen Intern Med 2006;21(suppl 2):S14 S20.

229. Berenholtz S, Pronovost PJ. Barriers to translating evidence into practice. Curr Opin Crit Care 2003;9(4):321-325.

230. Bouadma L, Mourvillier B, Deiler V, et al. Changes in knowledge, beliefs, and perceptions throughout a multifaceted behavioral program aimed at preventing ventilator-associated pneumonia. Intensive Care Med 2010;36(8):1341-1347.

231. Bassi GL, Ferrer M, Saucedo LM, Torres A. Do guidelines change outcomes in ventilator-associated pneumonia? Curr Opin Infect Dis 2010;23(2):171-177.

232. Lyerla F. Design and implementation of a nursing clinical decision support system to promote guideline adherence. Comput Inform Nurs 2008;26(4):227-233.

233. Sinuff T, Muscedere J, Cook D, Dodek P, Heyland D. Ventilator-associated pneumonia: improving outcomes through guideline implementation. J Crit Care 2008;23(1):118-125.

234. Omrane R, Eid J, Perreault MM, et al. Impact of a protocol for prevention of ventilator-associated pneumonia. Ann Pharmacother 2007;41(9):1390-1396.

235. Zaydfudim V, Dossett LA, Starmer JM, et al. Implementation of a real-time compliance dashboard to help reduce SICU ventilator-associated pneumonia with the ventilator bundle. Arch Surg 2009;144(7):656-662.

236. Salahuddin N, Zafar A, Sukhyani L, et al. Reducing ventilatorassociated pneumonia rates through a staff education pro-. gramme. J Hosp Infect 2004;57(3):223-227.

237. Westwell S. Implementing a ventilator care bundle in an adult intensive care unit. Nurs Crit Care 2008;13(4):203-207.

238. Pinto A, Burnett $S$, Benn J, et al. Improving reliability of clinical care practices for ventilated patients in the context of a patient safety improvement initiative. J Eval Clin Pract 2011;17(1):180187.

239. Guyatt GH, Oxman AD, Vist GE, et al. GRADE: an emerging consensus on rating quality of evidence and strength of recommendations. BMJ 2008;336(7650):924-926.

240. GRADE. Canadian Task Force on Preventive Health Care website. http://canadiantaskforce.ca/methods/grade/. Accessed December 31, 2013.

241. Rosenthal VD, Rodriguez-Calderon ME, Rodriguez-Ferrer M, et al. Findings of the International Nosocomial Infection Control Consortium (INICC), part II: impact of a multidimensional strategy to reduce ventilator-associated pneumonia in neonatal intensive care units in 10 developing countries. Infect Control Hosp Epidemiol 2012;33(7):704-710. 